\title{
Macroeconomic Derivatives: An Initial Analysis of Market-Based Macro Forecasts, Uncertainty, and Risk
}

\author{
Refet S. Gürkaynak \\ Bilkent University \\ Justin Wolfers \\ University of Pennsylvania \\ CEPR, IZA, and NBER
}

September 2005

Working Paper 2005-26

http://www.frbsf.org/publications/economics/papers/2005/wp05-26bk.pdf

The views in this paper are solely the responsibility of the authors and should not be interpreted as reflecting the views of the Federal Reserve Bank of San Francisco or the Board of Governors of the Federal Reserve System. 


\title{
Macroeconomic Derivatives: An Initial Analysis of Market-Based Macro Forecasts, Uncertainty, and Risk ${ }^{*}$
}

\author{
Refet S. Gürkaynak \\ Bilkent University \\ refet@bilkent.edu.tr
}

\author{
Justin Wolfers \\ University of Pennsylvania \\ CEPR, IZA, and NBER \\ jwolfers@wharton.upenn.edu
}

\begin{abstract}
In September 2002, a new market in "Economic Derivatives" was launched allowing traders to take positions on future values of several macroeconomic data releases. We provide an initial analysis of the prices of these options. We find that market-based measures of expectations are similar to survey-based forecasts although the market-based measures somewhat more accurately predict financial market responses to surprises in data. These markets also provide implied probabilities of the full range of specific outcomes, allowing us to measure uncertainty, assess its driving forces, and compare this measure of uncertainty with the dispersion of point-estimates among individual forecasters (a measure of disagreement). We also assess the accuracy of market-generated probability density forecasts. A consistent theme is that few of the behavioral anomalies present in surveys of professional forecasts survive in equilibrium, and that these markets are remarkably well calibrated. Finally we assess the role of risk, finding little evidence that risk-aversion drives a wedge between market prices and probabilities in this market.
\end{abstract}

September 15, 2005

\footnotetext{
* The authors would like to thank Jeffrey Crilley and Banu Demir for excellent research assistance. Thanks also to Chris Carroll, Frank Diebold, John Fernald, Jeffrey Frankel, Jose Lopez, Glenn Rudebusch, Betsey Stevenson, Adam Szeidl, Jonathan Wright, and Eric Zitzewitz for useful discussions and to Bill Cassano and Kevin Keating of Goldman Sachs for helping us with institutional detail. This paper was partly written while Gürkaynak was at the Federal Reserve Board. He thanks that institution for the outstanding research environment it provided. Wolfers gratefully acknowledges the support of a Hirtle, Callaghan and Co. - Arthur D. Miltenberger Research Fellowship, Microsoft Research, the Zell/Lurie Real Estate Center, and the Mack Center for Technological Innovation. Data and programs used in this paper are available at: www.nber.org/ jwolfers.
} 


\section{Introduction}

In 1993 Robert Shiller forcefully argued for the creation of a new set of securities tied to the future path of the macroeconomy. He argued that existing equity markets represent future claims on only a small fraction of future income, and that active "macro markets" would allow for more effective risk allocation, allowing individuals to insure themselves against many macroeconomic risks.

In October 2002, Goldman Sachs and Deutsche Bank set up the first markets tied directly to macroeconomic outcomes; they call these products "Economic Derivatives." These new markets allow investors to purchase options whose payoff depends on growth in non-farm payrolls, retail sales, levels of the Institute for Supply Management's manufacturing diffusion index, initial unemployment claims and the Euro-area harmonized CPI. New U.S.-based markets have recently been created for GDP and the international trade balance, and plans are underway for securities on U.S. CPI. ${ }^{1}$

In this market "digital" or "binary" options are traded, allowing traders to take a position on whether economic data will fall in specified ranges, thereby providing marketbased measures of investors' beliefs about the likelihoods of different outcomes. That is, the option prices can be used to construct a risk-neutral probability density function for each data release. Until the introduction of these Economic Derivatives such information was unavailable and probabilistic or density forecasts still remain quite rare.

We now have data for the first $2^{1 / 2}$ years of this market, and use these to provide an initial analysis. Given that we have only 153 data releases, many of our results will be suggestive. To preview our findings, in section 3 we find that central tendencies of marketbased forecasts are very similar to, but more accurate than surveys. Further, financial market responses to data releases are also better captured by surprises measured with respect to market-based expectations than survey-based expectations, again suggesting that they better capture investor expectations. Some behavioral anomalies evident in survey-based expectations - such as forecastable forecast errors - are notably absent from market-based forecasts.

\footnotetext{
${ }^{1}$ Beyond these markets, the Chicago Board of Trade is offering federal funds rate futures and options and the Chicago Mercantile Exchange has a thinly traded CPI futures contract. Online markets such as Hedgestreet and Tradesports also offer an array of economic derivatives to retail investors.
} 
The Economic Derivatives market prices options on many different outcomes, allowing us to assess forecasts of a full probability distribution. In section 4 we compare the dispersion of the option- and survey-based distributions, and exploit the unique feature of our data that allows us to address the distinction between disagreement and uncertainty. Distributions of survey responses are measures of disagreement, or heterogeneity of beliefs, across respondents. Measuring uncertainty requires knowing how much probability agents attribute to outcomes away from the mean expectation and economic derivatives prices at different strikes provide exactly that information. Although there appears to be some correlation between disagreement and uncertainty, we find that on a release-by-release basis disagreement is not a good proxy for uncertainty. The time series of market-based measures of uncertainty also provides some evidence in favor of the view that (at least market participants believe that) non-farm payrolls and retail sales follow GARCH-like processes. In section 5 we move beyond the first and second moments of the distribution, analyzing the efficacy of these option prices as density forecasts.

While most of our analysis proceeds as if market-prices correspond one-for-one with probabilities, in section 6 we ask whether it is reasonable to expect risk aversion to drive a wedge between prices and probabilities. We find that the risk premium is in most cases sufficiently small that it can be ignored for many applications. Finally, we investigate the extent to which pricing of Economic Derivatives can provide an informative estimate of the degree of risk aversion of investors.

We view part of our contribution as simply introducing these fascinating data to the research community and thus in the next section we provide some institutional background on the details of the contracts traded, and on the market clearing mechanism.

\section{The Market for Economic Derivatives}

The institutional features of these new macro markets are worthy of some comment. Economic derivatives are securities with payoffs based on macroeconomic data releases. Nonfarm payrolls options, for example, settle when the employment report is released and the payrolls number is known.

The standard instruments traded are a series of digital (binary) options. The digital call (put) options pay $\$ 1$ if the release is above (below) the strike. Typically around 10-20 different 
options are traded, each at different strike prices. Both puts and calls are traded for each data release. For transparency we will focus on the price of a "digital range" - a contract paying $\$ 1$ if the announced economic number lies between two adjacent strike prices. Other types of options, such as digital puts and calls, capped vanilla options and forwards, are also traded in these markets. Each of these can be expressed as portfolios of digital ranges and are priced as such.

Figure 1 shows the prices of digital ranges from the May 12, 2005 auction (more on auctions below) which traded on what the monthly percentage change in retail sales (excluding autos) in April 2005 would be. The data was released later in the same day. Assuming riskneutrality (which we will assume and defend in section 6), this histogram corresponds to the forecast probability distribution of the possible outcomes of this release. The mean of the distribution, the market's expectation, was 0.72 percent, compared to the mean survey forecast of 0.5 percent. In the event, the released value came in at 1.07 percent, closer to the marketimplied expectation. Assuming that probability is distributed uniformly within each bin, these market prices suggest that investors attributed about a 22 percent probability to the release coming in as high or higher. The major novelty of the economic derivatives market is that it allows the calculation of this implied probability.

While most financial markets operate as a continuous double auction, the market for economic derivatives is run as a series of occasional auctions, reflecting an attempt to maximize liquidity. ${ }^{2}$ The auction mechanism is also noteworthy as it is a pari-mutuel system. That is, for a given strike price all "bets" (puts and calls) that the specified outcome either will or will not occur are pooled; this pool is then distributed to the winners in proportion to the size of their bet (the number of options purchased). ${ }^{3}$ As such, the equilibrium price of these binary options is not known at the time the orders are made; indeed, it is only known when the last trade has occurred. Throughout the auction period (usually an hour) indicative price estimates are posted, reflecting what the price would be were no more orders to be made.

\footnotetext{
${ }^{2}$ Currently every order must go through Goldman Sachs, Deutsche Bank, or ICAP (an interdealer broker). As of the writing of this paper an agreement was in place to involve the CME in the auction process.

${ }^{3}$ The transaction cost - the fee paid to Goldman Sachs and Deutsche Bank - is one percent of the notional amount (one cent per digital option) capped at ten percent of the price of the option.
} 
Figure 1. State-Price Distribution for the April 2005 Retail Sales Release

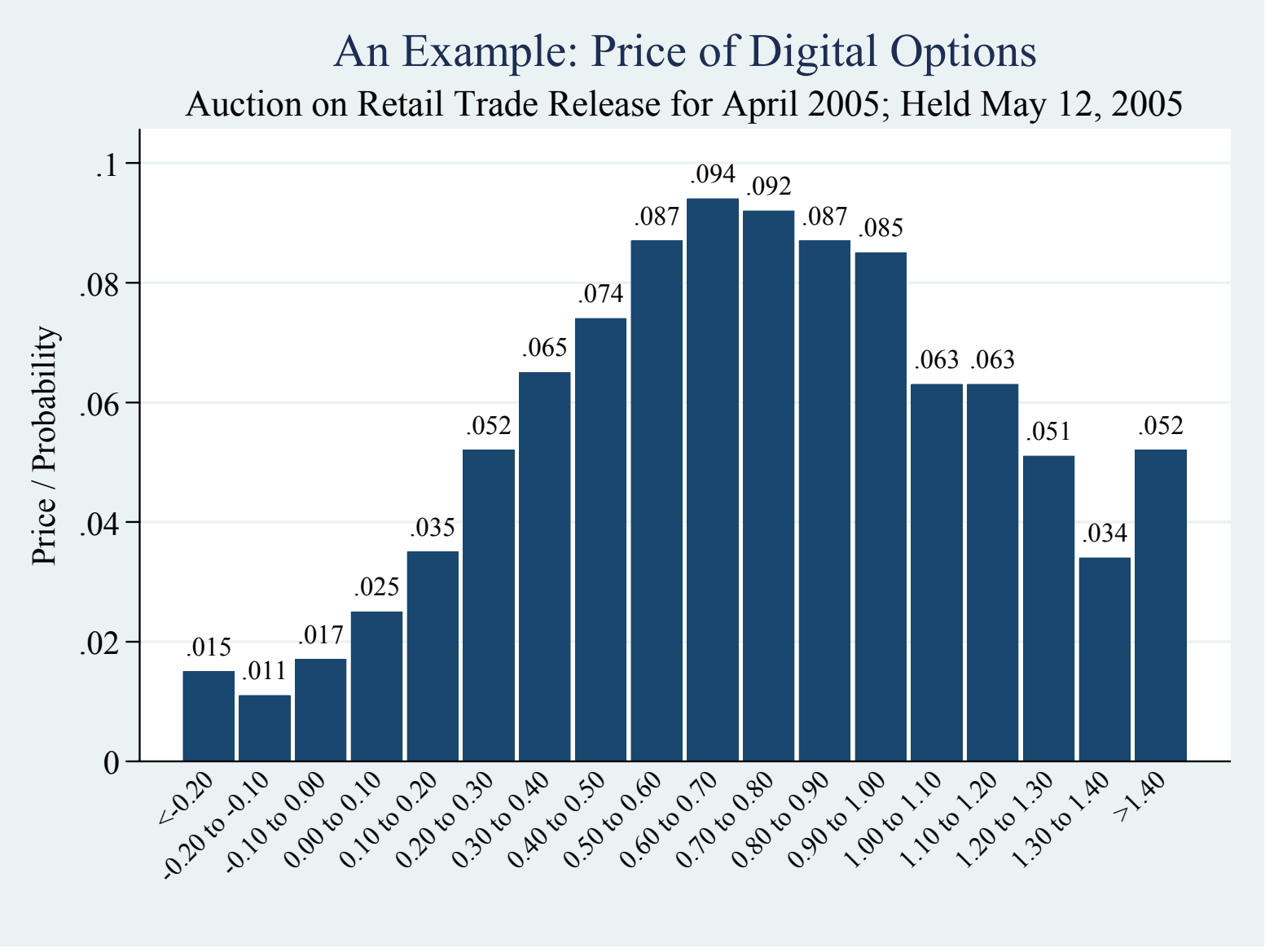

The use of pari-mutuel systems is unusual in financial markets, but common in horse race betting. Eisenberg and Gale (1959) provide useful results on the existence and uniqueness of equilibrium in such settings. The one important difference from horse race betting is that in the Economic Derivatives market it is possible to enter limit orders. This yields the possibility of multiple equilibria, which is resolved by an auction-clearing algorithm that chooses the equilibrium price vector that maximizes total trades. ${ }^{4}$ As in traditional Dutch auctions, all trades (at a given strike) that take place are executed at the same price, regardless of the limit price.

This pari-mutuel mechanism is useful because it expands the number of ways to match buyers with sellers. While traders can be matched if one buyer's demand for calls matches

\footnotetext{
${ }^{4}$ The auction clearing pari-mutuel algorithm, called "Parimutuel Derivative Call Auction technology" is patented by Longitude Inc., who also license their product to create markets in mortgage prepayment speeds and natural gas and crude oil inventories (see Baron and Lange, 2003, for more on this algorithm).
} 
another trader's demand for puts, the system does not require this. The horse track betting analogy is useful: even if nobody "sells" a given horse, as long as people bet on different horses the betting market clears. Similarly, buying a given digital range can be thought of as shorting all other outcomes and therefore having investors bidding at different strikes allows the pari-mutuel algorithm to clear the market and generate much greater volume.

In the economic derivatives market, option payoffs are determined with reference to a particular data release. Thus the payoff is based on, for example, the initial BLS estimate of growth in non-farm payrolls, rather than the best estimate of the statistical agencies (which will be subject to revision for years to come). In this sense these options provide hedges against event risk, where the events are data releases.

The events/auctions that are covered in the empirical analysis of this paper are growth of non-farm payrolls, the Institute for Supply Management manufacturing diffusion index (a measure of business confidence), change in retail sales ex-autos, and initial jobless claims. Options on GDP and trade balance releases commenced subsequent to our data collection efforts. Options on the Eurozone Harmonized Index of Consumer Prices also exist, but unfortunately we lack the high frequency financial market data for European securities required to analyze these data. Of the four markets that we do analyze, the non-farm payrolls market is the most liquid; business confidence and retail sales markets have liquidity comparable to each other but are less liquid. Initial claims options are the least liquid, however because this is a weekly release we have the largest number of observations in this market. ${ }^{5}$

Typically these auctions have taken place in the morning of the data release and they were sometimes preceded by another auction on the same release one or two days prior (non-farm payrolls auctions are held on both the morning the data are released and one day before). ${ }^{6,7}$ Thus economic derivatives provide hedging opportunities against only very high frequency movements - event risk - and really cannot be said to provide the sorts of business cycle frequency risk-sharing opportunities envisioned by Shiller. We return to a more careful assessment of the role of risk in these markets in section 6. But first we focus on the uses of market prices as forecasts.

\footnotetext{
${ }^{5}$ Auctions of initial claims options are not held for the releases that immediately precede the employment report. Our data set consists of 33 non-farm payrolls auctions, 30 business confidence auctions, 26 retail trade auctions, and 64 initial claims auctions.

${ }^{6}$ Some auctions on European inflation take place two months prior to the data release.

${ }^{7}$ When more than one auction was held for a single data release, we analyze data from the latest auction.
} 


\section{The Accuracy of Market-based Forecasts}

We begin by comparing forecasts generated by the Economic Derivatives market with an alternative information aggregator, the "survey forecast" released by Money Market Services (MMS) on the Friday before a data release. ${ }^{8}$ Specifically, we compare the mean forecast from each mechanism, although our results are insensitive to the choice of mean versus median forecasts. For the MMS forecast, the "consensus" forecast typically averages across around 30 forecasters. For the market-based forecast, we aggregate across the distribution of outcomes and calculate the distribution's mean assuming that the probability distribution is uniform within each bin (boundaries of bins are defined by adjacent strikes). ${ }^{9}$ As such, we implicitly assume that the price of a digital option is equal to the average belief that the specified outcome occurs. Wolfers and Zitzewitz (2005) discuss the relationship between prediction market prices and beliefs. We return to this issue in later sections, showing that ignoring risk aversion does very little violence to the data.

Figure 2 shows the relative forecasting performance of the survey- and market-based forecasts. Visual inspection suggests that the market-based forecast mildly dominates the survey forecast, a fact verified formally in Table 1.

\footnotetext{
${ }^{8}$ MMS was acquired by Informa in 2003 and no longer exists; Action Economics is now providing the same survey service. We use the MMS numbers for most of our sample and the Action Economics survey for the more recent period. Bloomberg survey numbers were used to fill some gaps. Despite using more than one source, we call our survey numbers "the MMS survey" as most of our data is from this source. The MMS survey sample consists mainly of professional economists working in financial markets, and many of the firms surveyed are probably also participants in the economic derivatives market.

${ }^{9}$ More specifically, throughout the paper we treat the distribution as discrete, assuming that all probability mass occurs at the midpoint of the relevant bin. For the tails we impute an upper- and lower-bound so that the midpoint would be equal to the mean of that bin if the pdf were normal. Our results are invariant to different treatments of tail probabilities.
} 
Figure 2. Comparing Forecast Performance

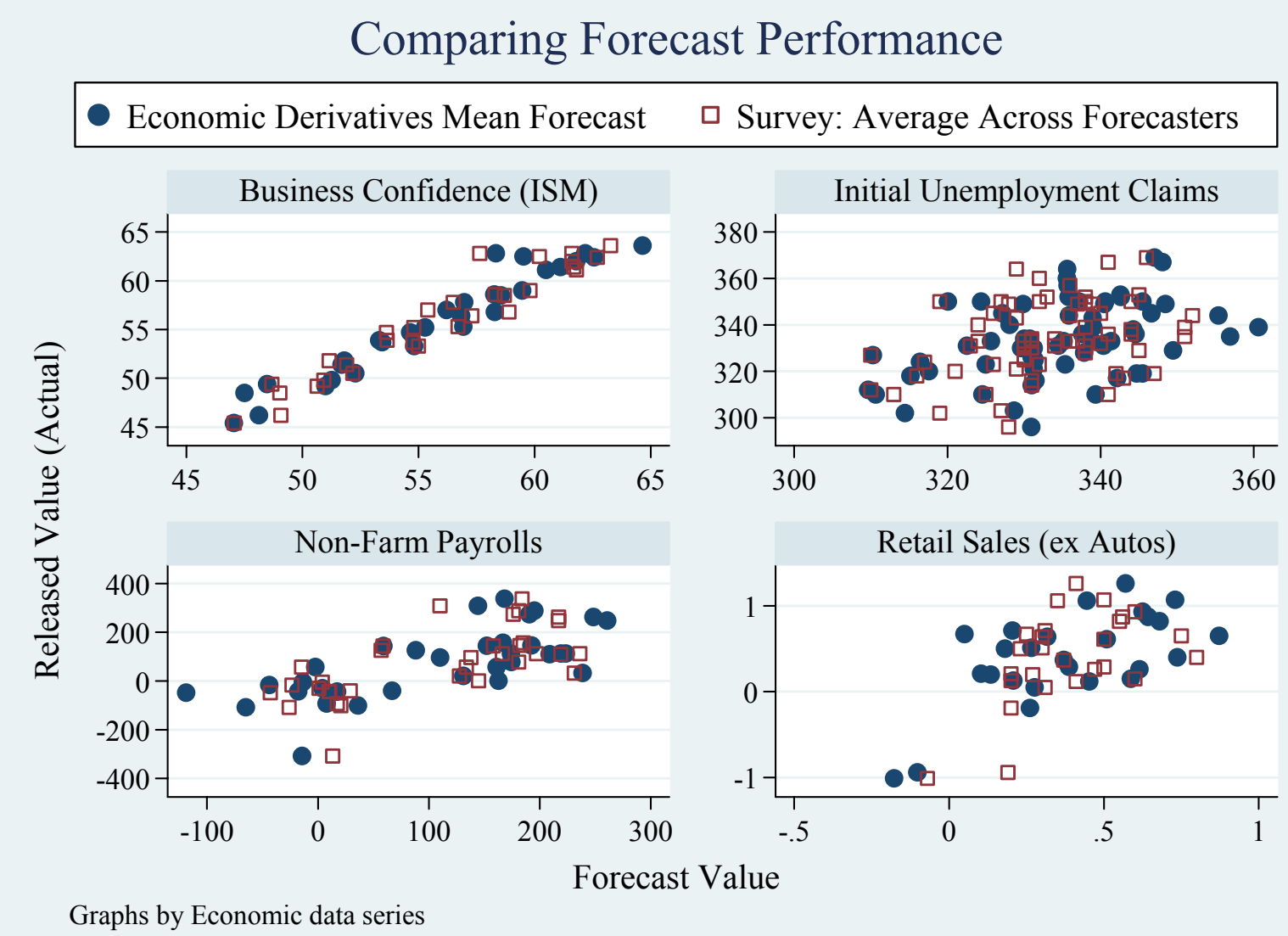

Table 1 examines two specific measures of forecast accuracy, the mean absolute error and the root mean squared error, contrasting the performance of the Economic Derivatives market and the survey respondents. Each column reports these summary statistics for a different data series. In order to provide some comparability of magnitudes across columns we normalize the scale of each by dividing our measures of forecast errors by the historical standard deviation of survey forecast errors over an earlier period. ${ }^{10}$ Thus, the units in the table can be read as measures of forecast errors relative to an historical norm. This scaling makes the magnitudes sufficiently comparable that we can pool our observations across data series in the final column.

\footnotetext{
${ }^{10}$ In order to maintain a non-overlapping sample, we calculated the standard deviation of the survey-based forecast errors for samples ending in October 2002. The "historical" sample begins in January 1990 for nonfarm payrolls and retail sales, in July 1991 for ISM, and in July 1997 for initial claims . The historical standard errors of these forecasts are 115,600 non-farm payroll jobs, 18,500 initial unemployment claims, $0.37 \%$ growth in retail sales and 1.99 points of the ISM index.
} 
Table 1: Comparing the Accuracy of Mean Forecasts

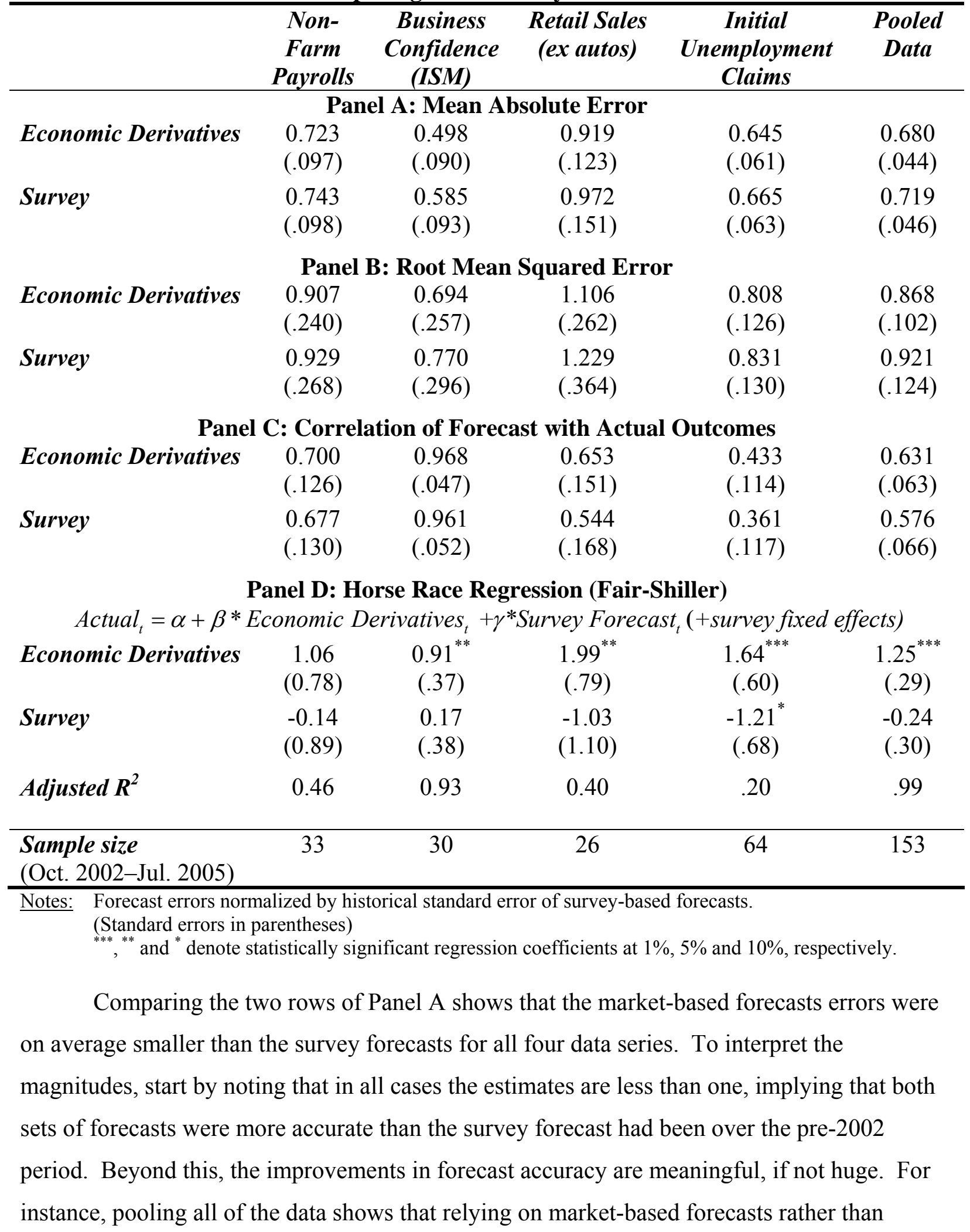


survey forecasts would have reduced the size of forecast errors by 0.04 , which by virtue of the scaling is equivalent to $5 \frac{1}{2} \%$ of the average forecast error over the preceding decade. While meaningful, this reduction is not statistically significant. Panel B shows that analyzing the root mean squared error yields roughly similar results. In Panel C we compare the correlation of each forecast with actual outcomes. (Naturally these correlations can also be interpreted as the coefficient from a regression of standardized values of the outcome on standardized values of the forecast.) Each of these coefficients is statistically significant, suggesting that each forecast has substantial unconditional forecasting power. Even so, the market-based forecast is more highly correlated with outcomes than the consensus forecast for all four data series.

Panel D turns to a regression-based test of the information content of each forecast following Fair and Shiller (1990). Naturally there is substantial collinearity, as the market- and consensus-based forecasts are quite similar. Even so, we find rather compelling results. A coefficient of unity for the market-based forecast cannot be rejected for any of the indicators. By contrast, conditioning on the market-based forecast renders the survey forecast uninformative, and in three of four cases the survey-based forecast is not statistically different from zero and in the one case in which it is significant, it has a perverse negative coefficient. In the final column we pool the forecasts to obtain more precise estimates and again the market-based forecast dominates, and this difference is both statistically and economically significant.

These findings are probably partly due to the fact that the economic derivatives auction occurs on the morning of the data release, while the survey takes place up to a week before. Thus, option prices incorporate more information than was available to survey respondents. In an attempt to partly ameliorate this information advantage, we also re-ran our regressions in Panel D, controlling for two indicators of recent economic news: the change in equity prices and bond yields between the market close on the night prior to the release of the survey data to the night before the economic derivatives auction. These indicators for the release of relevant news were typically insignificant, and our main conclusions were not much altered by this control.

It seems likely that the improved performance is due to the market effectively weighting a greater number of opinions, or more effective information aggregation as market participants are likely more careful when putting their money where their mouth is. 
We next ask which forecast aggregator better predicts the financial market reactions to the release of economic statistics. Or alternatively phrased, we ask: which forecast best embeds the forecasts of the equity and bond markets? In Figures $3 \mathrm{a}$ and $3 \mathrm{~b}$ we show the shortterm change in the S\&P 500 and the 10-year Treasury note yield that result from the release of economic news. The solid dots measure the innovation as the deviation of the announced economic statistic from the economic derivatives forecast, while the hollow squares represent the innovation as the deviation from the consensus forecast.

Figure 3a. Equity Market Responses to Surprises

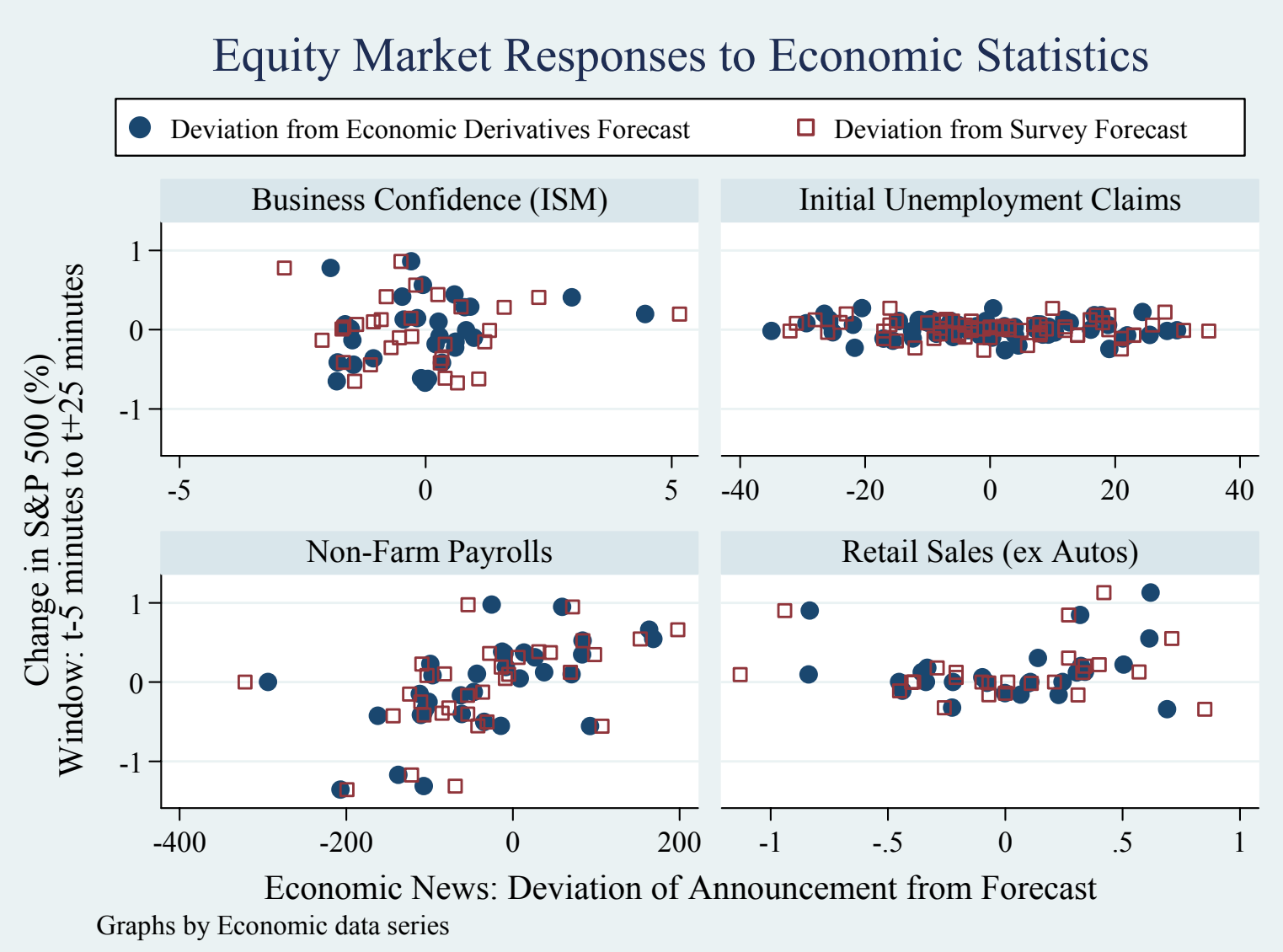


Figure 3b. Bond Market Responses to Surprises

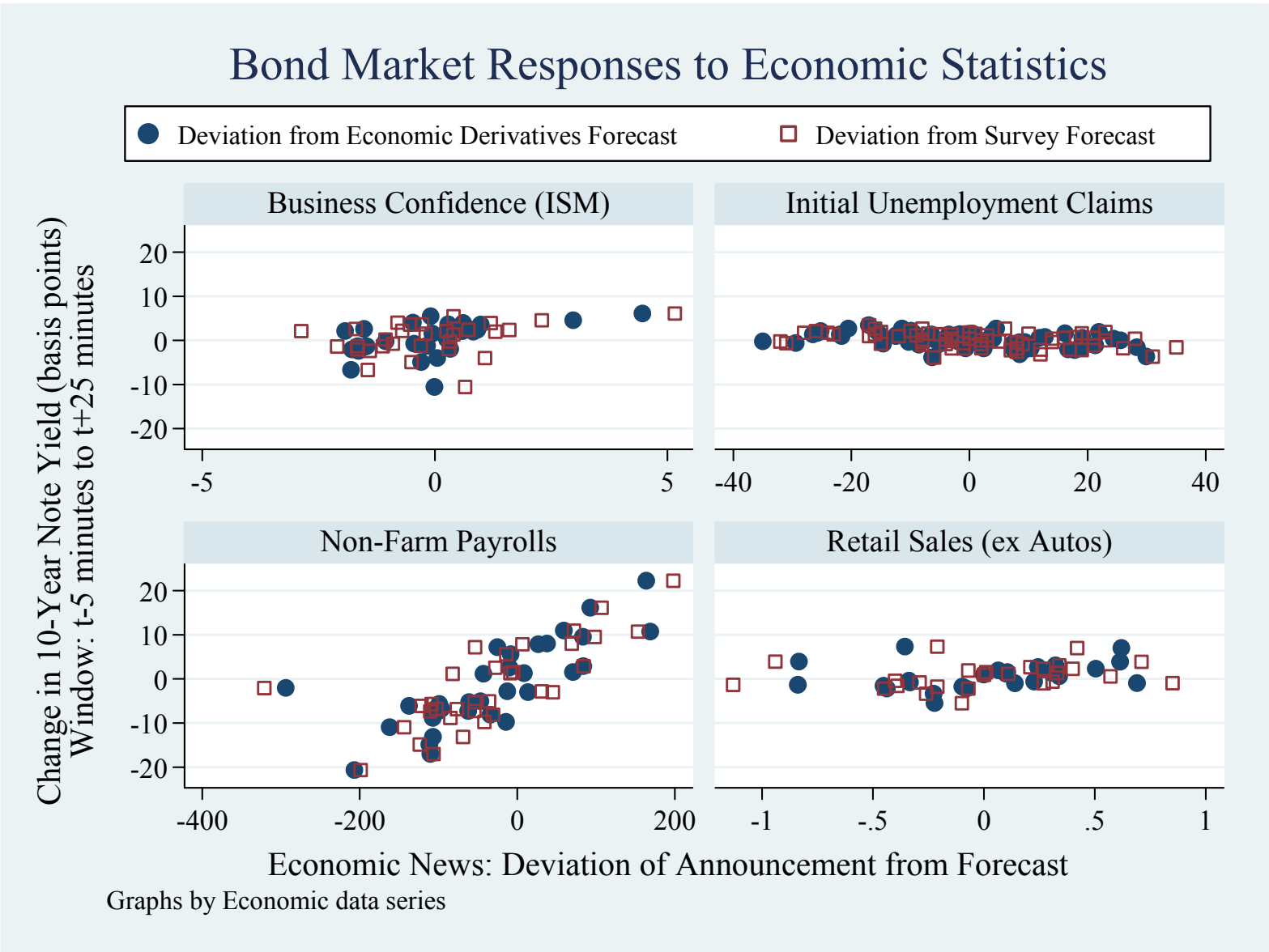

Table 2 formalizes the comparisons in Figures $3 a$ and $3 b$. Specifically, we run regressions of the form:

$\Delta$ Financial variable $_{t}=\alpha+\beta^{*}\left(\right.$ Actual $_{t}-$ Forecast $\left._{t}^{\text {Economic Derivs }}\right)+\gamma^{*}\left(\right.$ Actual $_{t}-$ Forecast $\left._{t}^{\text {Survey }}\right)$

We measure changes in stock and Treasury markets around a tight window, comparing financial market quotes 5 minutes prior the data release to 25 minutes after the event. ${ }^{11} \mathrm{We}$

\footnotetext{
${ }^{11}$ The intraday data we use help us isolate the market reaction to the data release in question with minimum noise. The yields we use are yields of on-the-run Treasury securities. The stock price changes are from S\&P futures contracts as the stock market is not open at 8.30 a.m. (EST), when the three of the four macroeconomic data series we are interested in are released (ISM is a 10.00 a.m. release). In taking the market snapshots, if there is no trade in a given security 5 minutes before the event, we search back in time until we find a trade or a settlement price. If there is no trade exactly 25 minutes after the event we again search back in time, until the data release moment. If there are no trades in this 25 minute interval we mark a zero change, assuming that if there was a surprise in the data release that changed the shadow price of a security there would have been a trade over this time period. We do not search for a trade forward in time so as to ensure that the price change we observe is not due to another
} 
analyze changes in implied Treasury yields, rather than changes in their prices, and report these changes in basis points; the stock market response is reported as percentage change. As before, we rescale our forecast error variables so that the estimates can be interpreted as the effect of a one-standard deviation forecast error.

Several patterns emerge in these data. First, comparing columns suggests that the nonfarm payrolls release has the largest effect on financial markets; retail trade and business confidence are also important, but the weekly initial claims data rarely moves markets by much. Comparing panels shows that the yields on longer-dated securities more reliably and more forcefully respond to the release of these economic statistics than do yields on short-term Treasury bills. It is likely that short-term interest rate expectations have been strongly anchored by Federal Reserve statements recently, reducing the sensitivity of short-term yields to data release surprises. The stock market also responds quite vigorously to non-farm payrolls. ${ }^{12}$ Lastly, comparing rows within each panel, financial markets appear to respond to economic data to the extent that they differ from the Economic Derivatives forecast; conditioning on this, the survey forecast has no statistically significant explanatory power in any individual regression.

To maximize our ability to test the joint significance across columns, we pool our data across all four economic series and run:

$$
\Delta \text { Financial variable }_{t}=\sum_{s \in \text { Economic series }} \alpha_{s}+\beta_{s}^{*}\left(\text { Actual }_{s, t}-\text { Forecast }_{s, t}^{\text {Consensus }}\right)+\gamma_{s} *\left(\text { Actual }_{s, t}-\text { Forecast }_{s, t}^{\text {Survey }}\right)
$$

The final column of Table 2 reports the joint statistical significance of the $\beta$ 's and the $\gamma$ 's, respectively. These joint tests clearly show that financial markets respond to the innovation as measured relative to the Economic Derivatives forecast and conditional on this, appear not to respond to the deviation of the data from the survey forecast.

event that took place later in the same day. The data set is described in detail in Gürkaynak, Sack, and Swanson (2005).

${ }^{12}$ Note that while a strong data release for an important statistic should unambiguously push yields up, the effect on stock prices is not as clear. The news that the state of the business cycle is better than expected will lift the S\&P index, but the associated increase in interest rates has a dampening effect on equities. 
Table 2: Predicting Market Responses to Economic Statistics

\begin{tabular}{|c|c|c|c|c|c|}
\hline & $\begin{array}{c}\text { Non- } \\
\text { farm } \\
\text { Payrolls }\end{array}$ & $\begin{array}{c}\text { Business } \\
\text { Confidence } \\
\text { (ISM) }\end{array}$ & $\begin{array}{c}\text { Retail } \\
\text { Sales } \\
\text { (ex autos) } \\
\end{array}$ & $\begin{array}{c}\text { Initial } \\
\text { Unemployment } \\
\text { Claims }\end{array}$ & $\begin{array}{c}\text { Joint } \\
\text { Significance } \\
(\text { F-test })\end{array}$ \\
\hline \multicolumn{6}{|c|}{$\Delta$ Financial variable $_{t}=\alpha+\beta^{*}\left(\right.$ Actual $_{t}-$ Forecast $\left._{t}^{\text {Economic Derivs }}\right)+\gamma^{*}\left(\right.$ Actual $_{t}-$ Forecast $\left._{t}^{\text {Survey }}\right)$} \\
\hline \multicolumn{6}{|c|}{ Panel A: 3 Month Treasury Bill } \\
\hline Economic Derivatives & $\begin{array}{l}4.41^{* *} \\
(1.71)\end{array}$ & $\begin{array}{l}0.428 \\
(.434)\end{array}$ & $\begin{array}{c}-0.094 \\
(.491)\end{array}$ & $\begin{array}{l}-0.087 \\
(.601)\end{array}$ & $\mathrm{p}=.0006$ \\
\hline Survey & $\begin{array}{l}-2.50 \\
(1.66)\end{array}$ & $\begin{array}{l}-0.166 \\
(.396)\end{array}$ & $\begin{array}{l}0.067 \\
(.442)\end{array}$ & $\begin{array}{l}-0.123 \\
(.585)\end{array}$ & $\mathrm{p}=.1374$ \\
\hline \multicolumn{6}{|c|}{ Panel B: 6 Month Treasury Bill } \\
\hline Economic Derivatives & $\begin{array}{l}6.21^{* *} \\
(2.40)\end{array}$ & $\begin{array}{l}1.034 \\
(.786)\end{array}$ & $\begin{array}{l}0.221 \\
(.751)\end{array}$ & $\begin{array}{l}-1.294 \\
(.785)\end{array}$ & $\mathrm{p}=.0004$ \\
\hline Survey & $\begin{array}{l}-3.47 \\
(2.33)\end{array}$ & $\begin{array}{l}-0.483 \\
(.769)\end{array}$ & $\begin{array}{l}-0.054 \\
(.675)\end{array}$ & $\begin{array}{l}0.976 \\
(.764)\end{array}$ & $\mathrm{p}=.1184$ \\
\hline \multicolumn{6}{|c|}{ Panel C: 2 Year Treasury Note } \\
\hline Economic Derivatives & $\begin{array}{c}12.61^{* *} \\
(6.04)\end{array}$ & $\begin{array}{c}3.96^{*} \\
(1.98)\end{array}$ & $\begin{array}{c}2.60 \\
(2.16)\end{array}$ & $\begin{array}{l}-1.40 \\
(1.15)\end{array}$ & $\mathrm{p}=.0016$ \\
\hline Survey & $\begin{array}{l}-2.50 \\
(5.87)\end{array}$ & $\begin{array}{l}-1.71 \\
(1.79)\end{array}$ & $\begin{array}{l}-1.73 \\
(1.94)\end{array}$ & $\begin{array}{c}0.42 \\
(1.11)\end{array}$ & $\mathrm{p}=.7841$ \\
\hline \multicolumn{6}{|c|}{ Panel D: 5 Year Treasury Note } \\
\hline Economic Derivatives & $\begin{array}{c}14.94^{* *} \\
(6.39)\end{array}$ & $\begin{array}{l}5.54^{* *} \\
(2.07)\end{array}$ & $\begin{array}{c}3.66 \\
(2.44)\end{array}$ & $\begin{array}{l}-3.17^{* *} \\
(1.22)\end{array}$ & $\mathrm{p}=.0001$ \\
\hline Survey & $\begin{array}{l}-3.90 \\
(6.21)\end{array}$ & $\begin{array}{l}-2.56 \\
(1.86)\end{array}$ & $\begin{array}{l}-2.53 \\
(2.19)\end{array}$ & $\begin{array}{l}2.06^{*} \\
(1.19)\end{array}$ & $\mathrm{p}=.4254$ \\
\hline \multicolumn{6}{|c|}{ Panel E: 10 Year Treasury Note } \\
\hline Economic Derivatives & $\begin{array}{l}10.40^{*} \\
(5.22)\end{array}$ & $\begin{array}{l}5.09^{* *} \\
(1.90)\end{array}$ & $\begin{array}{c}3.37 \\
(2.04)\end{array}$ & $\begin{array}{l}-2.12^{*} \\
(1.12)\end{array}$ & $\mathrm{p}=.0007$ \\
\hline Survey & $\begin{array}{l}-1.64 \\
(5.07)\end{array}$ & $\begin{array}{l}-2.53 \\
(1.71)\end{array}$ & $\begin{array}{l}-2.36 \\
(1.83)\end{array}$ & $\begin{array}{c}1.22 \\
(1.09)\end{array}$ & $\mathrm{p}=.4955$ \\
\hline Economic Derivatives & $\begin{array}{c}0.888^{* *} \\
(.386)\end{array}$ & $\begin{array}{l}\text { Panel F: S } \\
0.575^{* *} \\
(.226)_{* *}\end{array}$ & $\begin{array}{c}\mathbf{X} \mathbf{5 0 0} \\
0.434^{*} \\
(.252)\end{array}$ & $\begin{array}{l}-.106 \\
(.084)\end{array}$ & $\mathrm{p}=.0001$ \\
\hline Survey & $\begin{array}{l}-0.514 \\
(.375)\end{array}$ & $\begin{array}{c}-0.466^{* *} \\
(.204)\end{array}$ & $\begin{array}{l}-0.367 \\
(.227)\end{array}$ & $\begin{array}{l}0.092 \\
(.082)\end{array}$ & $\mathrm{p}=.0058$ \\
\hline
\end{tabular}

Notes: Dependent variables normalized by historical standard error of survey-based forecasts. (Standard errors in parentheses) ${ }^{* * *},{ }^{* *}$ and ${ }^{*}$ denote statistically significant at $1 \%, 5 \%$ and $10 \%$. For sample size, see Table 1.

In sum, Tables 1 and 2 establish that the Economic Derivatives forecast dominates the survey forecast (although survey forecasts perform quite well) both in predicting outcomes and in predicting market responses to economic news. Many previous papers have demonstrated 
that professional forecasters exhibit a range of predictable pathologies. For instance, Mankiw, Reis, and Wolfers (2003) analyze data on inflation expectations from the Survey of Professional Forecasters and the Livingstone Survey, finding that the median forecast yielded errors that were predictable based on recent economic developments, past forecast errors, or even the forecast itself. Were similar results to persist in the Economic Derivatives market, these predictable forecast errors would yield profitable trading opportunities.

In Table 3 we repeat many of the tests in that earlier literature, asking whether forecast errors are predictable based on a long-run bias (Panel A), on information in the forecast itself (Panel B), on previous forecast errors (Panel C), or on recent economic news (Panel D). We test the efficiency of the survey forecast and the Economic Derivatives forecasts separately, thus each cell in the table represents a separate regression. As before, we rescale the forecast errors by the historical standard deviation of the survey forecast errors for each indicator.

Each regression in Table 3 asks whether forecast errors are predictable; each panel tests different sets of predictors, and each column performs the test for a different economic indicator. The final column provides a joint F-test that the forecast errors are not predictable, aggregating across all four economic indicators in each row. In each succeeding panel we ask whether each forecast yields predictable on the basis of a simple constant term (Panel A), information in the forecast itself (Panel B), based on the forecast error from the previous month (Panel C), or based on recent economic information (Panel D). ${ }^{13}$ Only Panel C seems to show the only real evidence of behavioral biases, with the survey-based forecast yielding significantly negatively autocorrelated forecast errors, particularly for retail sales. Equally we should not overstate this result: while we cannot reject a null that market-based forecasts are efficient, we also cannot reject a null that they show the same pattern of predictable forecast errors as the survey-based forecasts.

\footnotetext{
${ }^{13}$ Panel D controls for the slope of the yield curve (measured as the difference between the 10 year and 3-month yields), and the change in the S\&P 500 over the preceding 10 trading days as regressors.
} 
Table 3: Tests of Forecast Efficiency

\begin{tabular}{|c|c|c|c|c|c|}
\hline & $\begin{array}{c}\text { Non- } \\
\text { farm } \\
\text { Payrolls } \\
\end{array}$ & $\begin{array}{c}\text { Business } \\
\text { Confidence } \\
\text { (ISM }\end{array}$ & $\begin{array}{c}\text { Retail } \\
\text { Sales } \\
\text { (ex autos) } \\
\end{array}$ & $\begin{array}{c}\text { Initial } \\
\text { Unemployment } \\
\text { Claims }\end{array}$ & $\begin{array}{c}\text { Joint } \\
\text { Significance } \\
(\text { F-test })\end{array}$ \\
\hline \multicolumn{6}{|c|}{ Panel A: Bias } \\
\hline \multicolumn{6}{|c|}{ Forecast error $_{t}=\alpha$} \\
\hline \multirow[t]{2}{*}{ Economic Derivatives } & $-0.29^{*}$ & -0.03 & 0.04 & -0.04 & $\mathrm{p}=.419$ \\
\hline & $(.15)$ & $(.13)$ & $(.22)$ & $(.10)$ & \\
\hline \multirow[t]{2}{*}{ Survey } & $-0.29^{*}$ & -0.06 & 0.03 & 0.05 & $\mathrm{p}=.371$ \\
\hline & $(.16)$ & $(.14)$ & $(.25)$ & $(.10)$ & \\
\hline \multicolumn{6}{|c|}{ Panel B: Internal efficiency } \\
\hline \multicolumn{6}{|c|}{$\begin{array}{l}\text { Forecast }_{\text {error }}=\alpha+\beta * \text { Forecast }_{t} \\
\text { [Square brackets shows test } \alpha=\beta=0]\end{array}$} \\
\hline \multirow[t]{3}{*}{ Economic Derivatives } & -0.049 & 0.078 & 0.309 & $-0.371^{* *}$ & $\mathrm{p}=.182$ \\
\hline & $(.174)$ & $(.053)$ & $(.310)$ & $(.167)$ & \\
\hline & {$[\mathrm{p}=.161]$} & {$[\mathrm{p}=.345]$} & {$[\mathrm{p}=.604]$} & {$[\mathrm{p}=.031)$} & \\
\hline \multirow[t]{3}{*}{ Survey } & 0.043 & 0.095 & 0.512 & $-0.398^{* *}$ & $\mathrm{p}=.173$ \\
\hline & $(.204)$ & $(.059)$ & $(.476)$ & $(.197)$ & \\
\hline & {$[\mathrm{p}=.196]$} & {$[\mathrm{p}=.273]$} & {$[\mathrm{p}=.564]$} & {$[\mathrm{p}=.127]$} & \\
\hline \multicolumn{6}{|c|}{ Panel C: Autocorrelation } \\
\hline \multicolumn{6}{|c|}{ Forecast error $_{t}=\alpha+\rho *$ Forecast error $_{t-1}$} \\
\hline \multirow[t]{2}{*}{ Economic Derivatives } & -0.091 & -0.008 & $-0.383^{*}$ & 0.002 & $\mathrm{p}=.186$ \\
\hline & $(.183)$ & $(.191)$ & $(.188)$ & $(.128)$ & \\
\hline \multirow[t]{2}{*}{ Survey } & -0.078 & 0.142 & $-0.500^{* *}$ & -0.074 & $\mathrm{p}=.016$ \\
\hline & $(.183)$ & $(.190)$ & $(.180)$ & $(.128)$ & \\
\hline \multicolumn{6}{|c|}{ Panel D: Information efficiency } \\
\hline \multicolumn{6}{|c|}{$\begin{array}{c}\text { Forecast error }_{t}=\alpha+\beta * \text { Slope of yield curve } \boldsymbol{t}_{t-1}+\gamma * \Delta S \& P 5_{000_{t-1, t-10}} \\
{[\text { Square brackets shows test } \beta=\gamma=0]}\end{array}$} \\
\hline \multirow[t]{5}{*}{ Economic Derivatives } & $\beta=-0.100$ & $\beta=0.287$ & $\beta=0.078$ & $\beta=0.102$ & $\mathrm{p}=.800$ \\
\hline & $(.229)$ & $(.186)$ & $(.322)$ & $(.121)$ & \\
\hline & $\gamma=0.051$ & $\gamma=-0.039$ & $\gamma=-0.073$ & $\gamma=-0.012$ & \\
\hline & $(.060)$ & $(.054)$ & $(.094)$ & $(.053)$ & \\
\hline & {$[\mathrm{p}=.640]$} & {$[\mathrm{p}=.241]$} & {$[\mathrm{p}=.735]$} & {$[\mathrm{p}=.677]$} & \\
\hline \multirow[t]{5}{*}{ Survey } & $\beta=-0.031$ & $\beta=0.390^{*}$ & $\beta=0.132$ & $\beta=0.137$ & $\mathrm{p}=.672$ \\
\hline & $(.237)$ & $(.201)$ & $(.359)$ & $(.123)$ & \\
\hline & $\gamma=0.046$ & $\gamma=-0.043$ & $\gamma=-0.076$ & $\gamma=-0.018$ & \\
\hline & $(.063)$ & $(.059)$ & $(.105)$ & $(.054)$ & \\
\hline & {$[\mathrm{p}=.759]$} & {$[\mathrm{p}=.127]$} & {$[\mathrm{p}=.737]$} & {$[\mathrm{p}=.502]$} & \\
\hline \multicolumn{6}{|c|}{ Panel E: Joint Test of all Predictors (p-value of joint significance) } \\
\hline \multicolumn{6}{|c|}{$\begin{aligned} \text { Forecast error }_{t}=\alpha+ & +\beta_{1} * \text { Survey Forecast } t_{t}+\beta_{2} * \text { Market Forecast } t_{t}+\beta_{3} * \text { Forecast error }_{t-1} \\
& +\beta_{4} * \text { Slope of yield curve } e_{t-1}+\beta_{5} * \Delta S \& P 500_{t-1, t-10}\end{aligned}$} \\
\hline Economic Derivatives & $\mathrm{p}=.900$ & $p=.129$ & $\mathrm{p}=.228$ & $\mathrm{p}=.015$ & $\mathrm{p}=.0664$ \\
\hline Survey & $\mathrm{p}=.625$ & $\mathrm{p}=.036$ & $\mathrm{p}=.017$ & $\mathrm{p}=.004$ & $p=.0003$ \\
\hline
\end{tabular}

Notes: Each cell represents a separate regression.

Dependent variables normalized by historical standard deviation of survey-based forecasts.

(Standard errors in parentheses) ${ }^{* * *},{ }^{* *}$ and ${ }^{*}$ denote statistically significant at $1 \%, 5 \%$ and $10 \%$. 
Finally in Panel E we combine each of the above tests, testing whether forecast errors are predictable based on the full set of possible predictors (including both the market- and survey-based forecasts themselves). On this score the superior performance of the marketbased forecasts is much more evident. The survey-based forecasts yield predictable forecast errors for three of the four statistical series; not surprisingly, the survey does best on non-farm payrolls, which is the most closely watched of these numbers. The market-based forecasts show no such anomalies except in the case of initial claims, which is easily the least liquid of these markets. Overall these results confirm the results in the earlier behavioral literature documenting anomalies in survey-based forecasts. Equally, they suggest that such inefficiencies are either absent, or harder to find in market-based forecasts.

This section compared the mean forecast from surveys and economic derivatives, with the basic finding that while surveys do well (despite some behavioral anomalies), markets do somewhat better in forecasting. If one is only interested in forecasting the mean, using surveys might suffice; however, Economic Derivatives provide a lot more information than just the mean forecast. Observing that the mean of the market-based probability distribution "works" the way it should is comforting and holds promise for the information content of the higher moments of the distribution, the subject of the next section.

\section{Disagreement and Uncertainty}

We now turn to analyzing the standard deviation of the state-price distribution. We will refer to this standard deviation as "uncertainty", reflecting the fact that this is the implied standard error of the mean forecast. Table 4 compares the market's average assessment of uncertainty with the realized root-mean-squared error of both the market- and survey-based forecasts over the same period. These results suggest that the market-based measure of uncertainty is reasonably well calibrated. We also include a third comparison: estimates by the official statistical agencies of the standard error of their measurements of these economic statistics, where available. Market expectations of the RMSE of forecast errors are only slightly larger than sampling error in the case of non-farm payrolls, and slightly smaller in the case of retail sales. 
Table 4: Expectations and Realizations of Forecast Accuracy

\begin{tabular}{lcccc}
\hline $\begin{array}{l}\text { RMSE of Forecasts } \\
\text { (or standard deviation of forecast } \\
\text { error) }\end{array}$ & $\begin{array}{c}\text { Non- } \\
\text { farm } \\
\text { Payrolls }\end{array}$ & $\begin{array}{c}\text { Business } \\
\text { Confidence } \\
\text { (ISM) }\end{array}$ & $\begin{array}{c}\text { Retail Sales } \\
\text { (ex autos) }\end{array}$ & $\begin{array}{c}\text { Initial } \\
\text { Unemployment } \\
\text { Claims }\end{array}$ \\
\hline $\begin{array}{l}\text { Expectations } \\
\quad \text { Market-implied standard deviation }\end{array}$ & 96.1 & 2.01 & 0.44 & 12.5 \\
$\begin{array}{l}\text { Realizations } \\
\text { SD of Market Forecast Errors }\end{array}$ & 100.7 & 1.40 & 0.42 & 15.1 \\
$\quad \begin{array}{l}\text { SD of Survey Forecast Errors } \\
\text { Sampling error }\end{array}$ & 103.7 & 1.55 & 0.46 & 15.5 \\
$\quad$ Standard error of official estimate & 81.5 & n.a. & 0.5 & n.a. \\
\hline
\end{tabular}

Notes: For estimates of the standard errors of the official estimates, see Wolfers and Zitzewitz (2004, p.115).

Explicit measures of uncertainty are rare in macroeconomics, so we compare this marketbased measure with the standard deviation of point forecasts across forecasters, and following Mankiw, Reis, and Wolfers (2003), we refer to the latter as "disagreement". The (previous) absence of useful data on uncertainty had led many researchers to analyze data on disagreement as a proxy for uncertainty. To date there has been very little research validating this approach, and indeed the only other measure of uncertainty we are aware of (from the Survey of Professional Forecasters) shows only weak co-movement with measures of disagreement (Llambros and Zarnowitz, 1987.)

Figure 4 shows results consistent with Llambros and Zarnowitz: disagreement and uncertainty co-move, but the correlation is not strong. The obvious difference in the levels is due to the fact that central expectations of respondents are close to each other even when each respondent is uncertain of their estimate.

In Table 5 we analyze these relationships a little more formally, regressing uncertainty against disagreement. Panel A shows that there is a statistically significant positive correlation between disagreement and uncertainty for all series except ISM. The final column shows the joint significance of the coefficients on disagreement, suggesting that the contemporaneous relationship is quite strong. Indeed, Chris Carroll has suggested that one can interpret these regressions as the first stage of a split-sample IV strategy, allowing researchers to employ disagreement as a proxy for uncertainty in another dataset. This, of course, depends on how high an $\mathrm{R}^{2}$ one views as sufficient in the first stage regression. 
Figure 4. Disagreement and Uncertainty

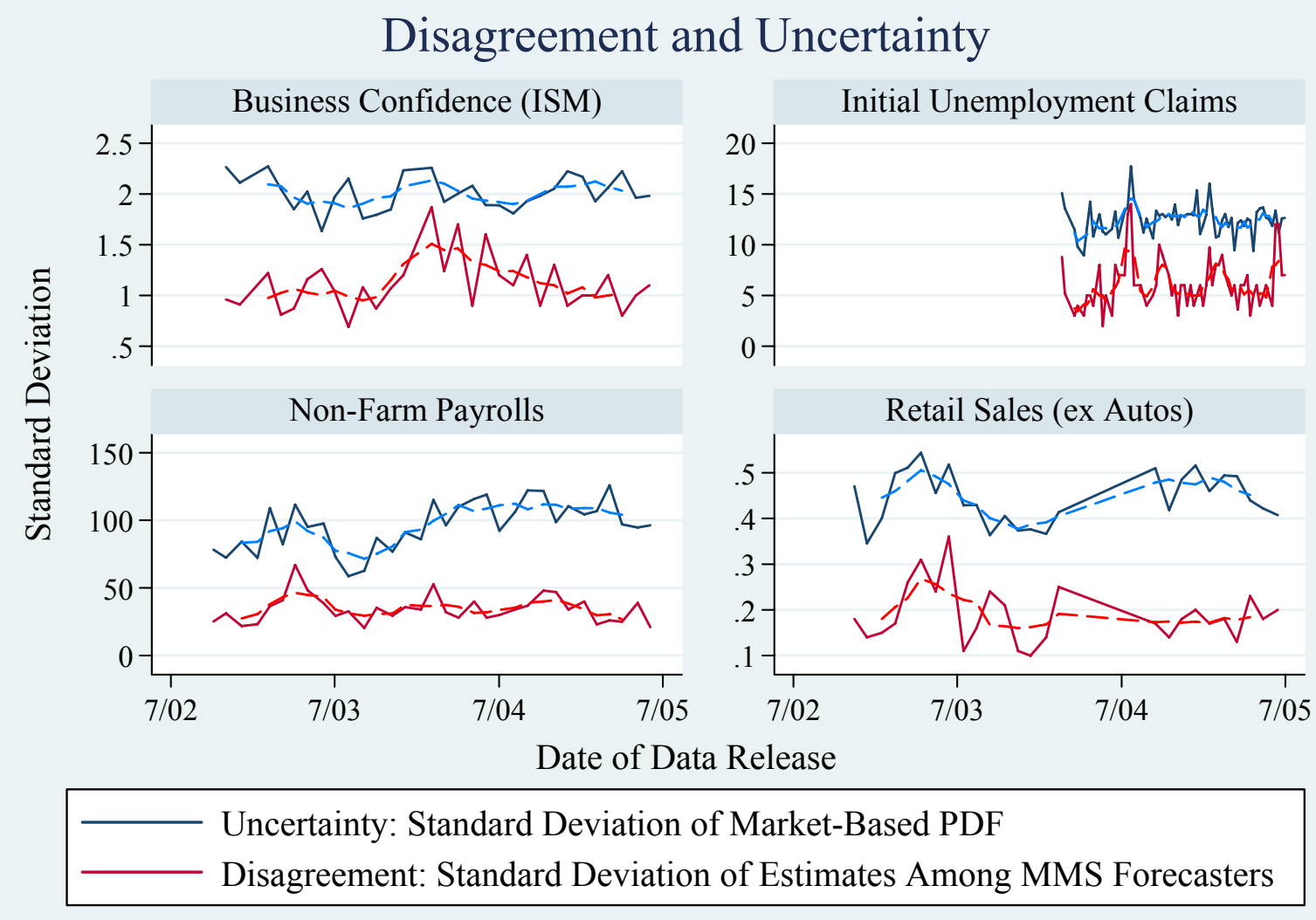

Dashed lines show 5-period centered moving averages

Panel B of this table carries out a similar exercise focusing on lower-frequency variation. In this case, disagreement and uncertainty are still correlated but this correlation is substantially weaker. The 5-period moving average of disagreement is a significant explanator of the 5-period moving average of uncertainty only for retail sales and initial claims. (Even this is overstates the strength of the relationship, as we do not correct the standard errors for the autocorrelation generated by smoothing.) Jointly testing the significance across all four indicators we find that the relationship between low frequency variation in disagreement and uncertainty is not statistically significant, and the $\mathrm{R}^{2 \text { s }} \mathrm{s}$ of these regressions are again sufficiently low and varied as to caution that disagreement might be a poor proxy for uncertainty in empirical applications. 
Table 5: Disagreement and Uncertainty

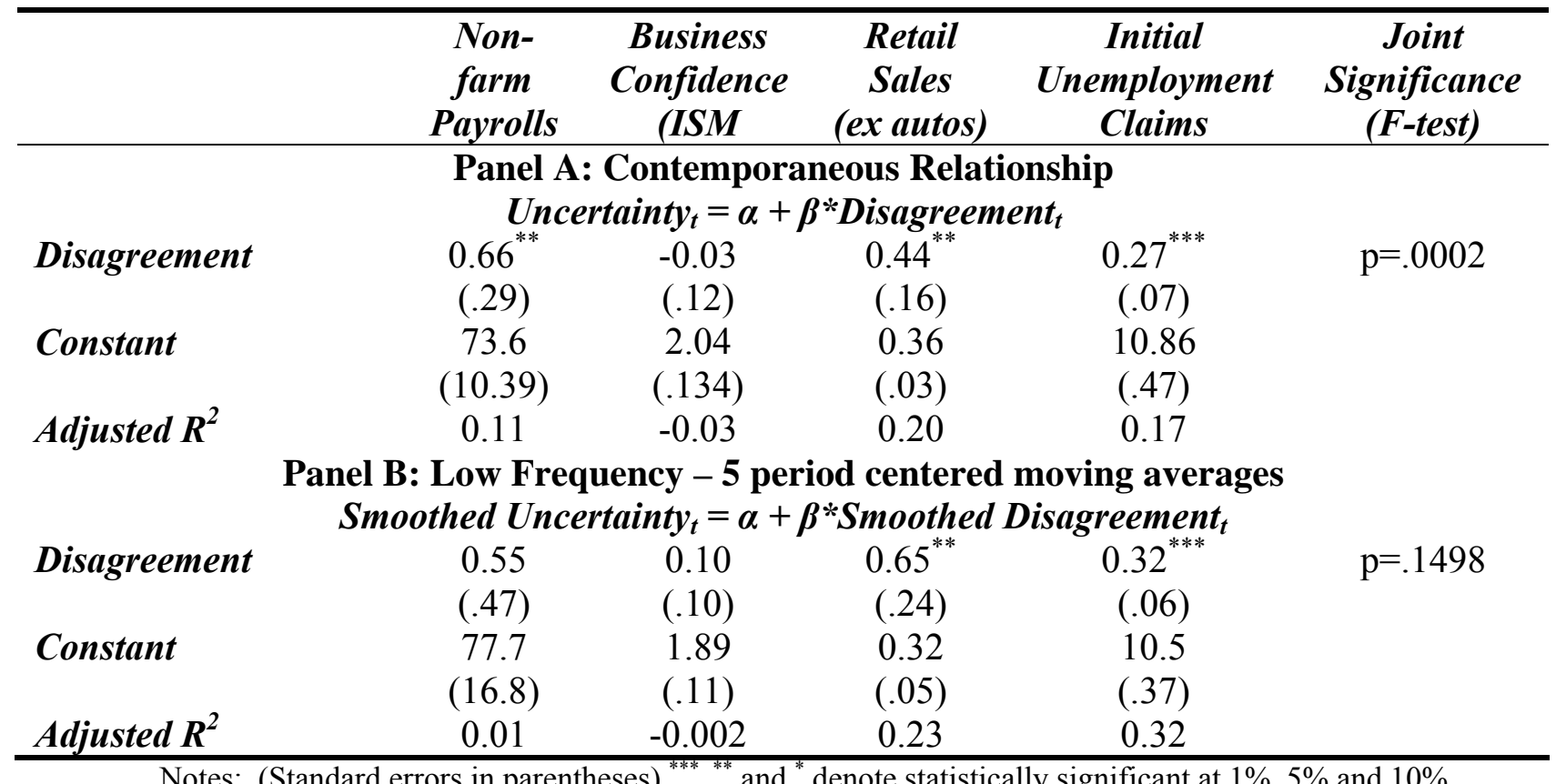

Notes: (Standard errors in parentheses) ${ }^{* * * * *},{ }^{* *}$ and ${ }^{*}$ denote statistically significant at $1 \%, 5 \%$ and $10 \%$.

Having demonstrated fairly substantial time series variation in uncertainty (albeit over a short period) naturally raises the question: What drives movements in uncertainty?

In Panel A of Table 6 we look to see whether any of the variation is explained by movements in expected volatility of equity markets. That is, our regressors include the closing price of CBOE's VIX index on the day prior to the economic derivatives auction, as well as the closing price one and two months prior (for the initial claims, these lags refer to one and two weeks earlier). As in tables 1-3, we rescale the uncertainty measure by the standard deviation of historical forecast errors to allow some comparability across columns. Panel A shows that for all four indicators the contemporaneous values of the implied volatility index is uncorrelated with uncertainty about forthcoming economic data. While a couple of specific lags are statistically significant, they suggest a somewhat perverse negative correlation between uncertainty and expected volatility in the stock market. This lack of correlation likely suggests that uncertainty is usually not about the fundamental state of the economy but about the particular data release-perhaps because the seasonal factors are sometimes more difficult to forecast. 
Table 6: Modeling Uncertainty

\begin{tabular}{|c|c|c|c|c|}
\hline & $\begin{array}{c}\text { Non-farm } \\
\text { Payrolls }\end{array}$ & $\begin{array}{c}\text { Business } \\
\text { Confidence } \\
\text { (ISM) }\end{array}$ & $\begin{array}{c}\text { Retail Sales } \\
\text { (ex autos) }\end{array}$ & Initial Claims \\
\hline \multicolumn{5}{|c|}{$\begin{array}{c}\text { Panel A: Uncertainty and Expected Volatility } \\
\text { Uncertainty }_{t}=\alpha+\beta_{1} * V I X_{t}+\beta_{2} * V I X_{t-1}+\beta_{3} * V I X_{t-2}\end{array}$} \\
\hline VIX $_{t}$ & $\begin{array}{l}0.76 \\
(.95)\end{array}$ & $\begin{array}{l}0.41 \\
(.72)\end{array}$ & $\begin{array}{c}0.04 \\
(1.07)\end{array}$ & $\begin{array}{l}0.10 \\
(.86)\end{array}$ \\
\hline VIX $_{t-1}$ & $\begin{array}{c}-1.93^{* *} \\
(.86)\end{array}$ & $\begin{array}{l}0.79 \\
(.69)\end{array}$ & $\begin{array}{l}1.15 \\
(1.27)\end{array}$ & $\begin{array}{c}-0.44 \\
(1.04)\end{array}$ \\
\hline $\mathbf{V I X}_{\mathrm{t}-2}$ & $\begin{array}{l}0.23 \\
(.80)\end{array}$ & $\begin{array}{c}-1.01^{*} \\
(.57)\end{array}$ & $\begin{array}{r}-0.93 \\
(.98)\end{array}$ & $\begin{array}{l}-0.22 \\
(.85)\end{array}$ \\
\hline Joint sig? & $\mathrm{p}=0.02$ & $\mathrm{p}=0.31$ & $\mathrm{p}=0.73$ & $\mathrm{p}=0.80$ \\
\hline Adjusted $R^{2}$ & 0.21 & 0.02 & -0.07 & -0.03 \\
\hline \multicolumn{5}{|c|}{ Panel B: Persistence } \\
\hline Uncertainty $_{t-1}$ & $\begin{array}{l}0.34^{*} \\
(.19)\end{array}$ & $\begin{array}{l}0.24 \\
(.19)\end{array}$ & $\begin{array}{l}0.43^{* 3} \\
(.23)\end{array}$ & $\begin{array}{l}0.20 \\
(.13)\end{array}$ \\
\hline Uncertainty $_{\mathrm{t}-2}$ & $\begin{array}{l}0.37^{*} \\
(.19)\end{array}$ & $\begin{array}{l}-0.26 \\
(.20)\end{array}$ & $\begin{array}{l}0.14 \\
(.23)\end{array}$ & $\begin{array}{l}0.01 \\
(.13)\end{array}$ \\
\hline Uncertainty $_{\mathrm{t}-3}$ & $\begin{array}{r}-0.12 \\
(.19)\end{array}$ & $\begin{array}{l}0.11 \\
(.19)\end{array}$ & $\begin{array}{r}-0.13 \\
(.21)\end{array}$ & $\begin{array}{c}-0.24^{*} \\
(.13)\end{array}$ \\
\hline Joint sig? & $\mathrm{p}=0.02$ & $p=0.45$ & $p=0.14$ & $\mathrm{p}=0.10$ \\
\hline Adjusted $\mathbf{R}^{2}$ & 0.24 & -0.01 & 0.12 & 0.06 \\
\hline \multicolumn{5}{|c|}{ 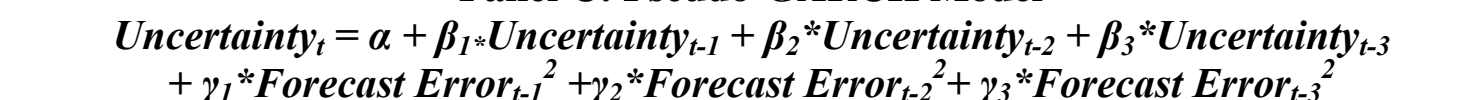 } \\
\hline Uncertainty & $\begin{array}{l}0.37^{*-1} \\
(.21)\end{array}$ & $\begin{array}{l}0.21 \\
(.22)\end{array}$ & $0.47^{*}$ & $\begin{array}{l}0.16 \\
(.13)\end{array}$ \\
\hline Uncertainty $_{\mathrm{t}-2}$ & $\begin{array}{l}0.38 \\
(.22)\end{array}$ & $\begin{array}{r}-0.12 \\
(.23)\end{array}$ & $\begin{array}{r}-0.10 \\
(.25)\end{array}$ & $\begin{array}{l}0.02 \\
(.13)\end{array}$ \\
\hline Uncertainty $_{t-3}$ & $\begin{array}{r}-0.13 \\
(.19)\end{array}$ & $\begin{array}{l}0.05 \\
(.20)\end{array}$ & $\begin{array}{l}0.12 \\
(.24)\end{array}$ & $\begin{array}{r}-0.20 \\
(.12)\end{array}$ \\
\hline Joint sig? & $\mathrm{p}=0.01$ & $\mathrm{p}=0.82$ & $\mathrm{p}=0.28$ & $p=0.26$ \\
\hline$F^{\prime}$ cast error ${ }_{t-1}^{2}$ & $\begin{array}{c}0.05^{* *} \\
(.02)\end{array}$ & $\begin{array}{l}0.02 \\
(.02)\end{array}$ & $\begin{array}{c}0.05^{* *} \\
(.03)\end{array}$ & $\begin{array}{c}0.03^{* *} \\
(.01)\end{array}$ \\
\hline$F^{\prime}$ cast error ${ }_{t-2}^{2}$ & $\begin{array}{l}0.02 \\
(.02)\end{array}$ & $\begin{array}{r}-0.02 \\
(.02)\end{array}$ & $\begin{array}{r}-0.03 \\
(.03)\end{array}$ & $\begin{array}{l}0.01 \\
(.01)\end{array}$ \\
\hline$F^{\prime}$ cast error ${ }_{t-3}^{2}$ & $\begin{array}{r}-0.01 \\
(.02)\end{array}$ & $\begin{array}{c}-0.00 \\
(0.02)\end{array}$ & $\begin{array}{r}-0.00 \\
(.02)\end{array}$ & $\begin{array}{r}-0.00 \\
(.01)\end{array}$ \\
\hline Joint sig? & $\mathrm{p}=0.05$ & $\mathrm{p}=0.41$ & $\mathrm{p}=0.21$ & $\mathrm{p}=0.11$ \\
\hline Adjusted $R^{2}$ & 0.38 & -0.009 & 0.21 & 0.11 \\
\hline n [Panel A, B/C] & {$[33,30]$} & {$[30,27]$} & {$[26,23]$} & {$[64,61]$} \\
\hline
\end{tabular}


VIX $_{\mathrm{t}}$ refers to the close of CBOE's VIX index on the day prior to the auction. VIX $\mathrm{t}_{\mathrm{t}-1}$ refers to the day prior to the previous data release. Uncertainty $\mathrm{t}_{\mathrm{t}-1}$ refers to the standard deviation of the state price distribution for the previous data release in that series. All of the uncertainty measures are rescaled by the historical standard deviation of forecast errors for that series.

Panel B also examines the persistence of uncertainty, and uncertainty about non-farm payrolls and retail sales appears to show some degree of persistence. Finally Panel C jointly tests whether uncertainty is a product of both past uncertainty and past realizations, as posited in GARCH models. Market assessments of the uncertainty in non-farm payrolls, retail sales, and initial claims appears to be well-described by these variables, although we find no such evidence for ISM. $^{14}$ Finally we ask whether these market-based measures of uncertainty actually predict the extent of forecast errors.

Figure 5 seems to suggest that uncertainty is not strongly related to larger (absolute) forecast errors (note that these forecast errors are standardized by their historical standard errors). We perform a more formal test in Table 7. If the uncertainty measure is appropriately calibrated, we should expect to see a coefficient of one in the regression of absolute forecast errors on uncertainty.

Overall Table 7 suggests that these tests have very little power. In no individual case is the absolute forecast error significantly correlated with the market-based measure of uncertainty. The final column pools the data, again finding no evidence of a significant correlation. That is, the data cannot reject the null that there is no information in the time series variation in market-based uncertainty that helps predict time series variation in forecast errors. On the other hand, the estimates are imprecise enough that, as the second row shows, we cannot reject a coefficient of unity for three out of the four series either.

\footnotetext{
${ }^{14}$ While Table 6 provides useful descriptive detail, it is silent on the issue of driving forces. There are potentially three important influences that may be driving variation in uncertainty about a particular economic statistic: fundamental uncertainty about the true underlying state of the economy, data-driven uncertainty whereby other data series have not spoken clearly about the state of the economy, and uncertainty about the extent of possible measurement error in the underlying economic statistic. Financial market responses to economic news can potentially help sort out which driving forces are important as economic news has its largest impact on beliefs (and hence on financial markets) when there is greater uncertainty about the true state of the economy. By contrast, traders will be more likely to discount the same sized shock if their uncertainty reflects concerns about measurement. Our statistical tests for these produced very imprecise estimates that we do not report, but we note this potential use of economic derivates based information.
} 
Figure 5. Uncertainty and Forecast Errors

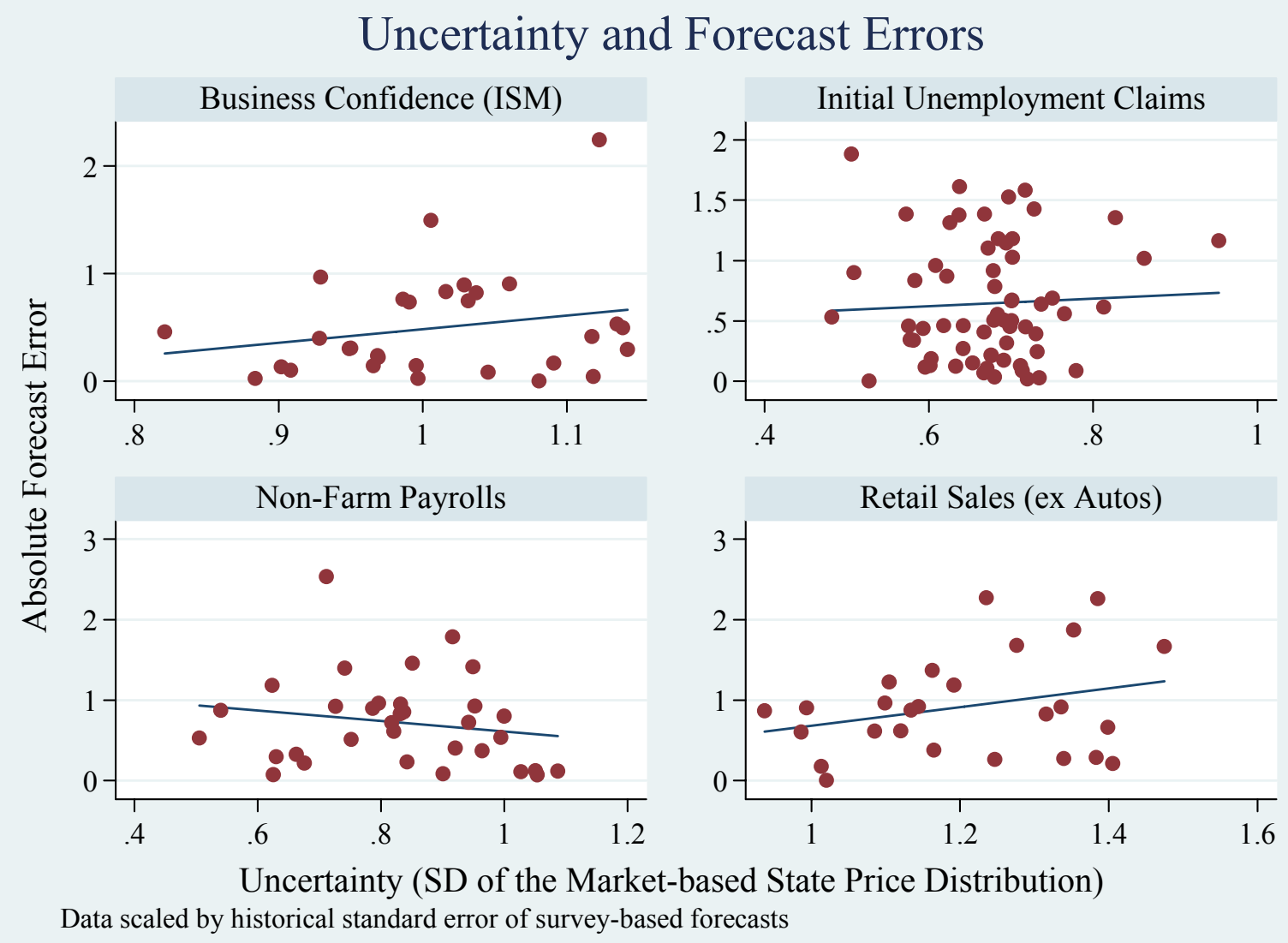

Table 7: Uncertainty and Forecast Errors

\begin{tabular}{|c|c|c|c|c|c|}
\hline & $\begin{array}{c}\text { Non- } \\
\text { farm } \\
\text { Payrolls } \\
\end{array}$ & $\begin{array}{c}\text { Business } \\
\text { Confidence }\end{array}$ & $\begin{array}{c}\text { Retail Trade } \\
\text { (ex autos) }\end{array}$ & Initial Claims & $\begin{array}{c}\text { Joint } \\
\text { Signif. } \\
\text { (F-test) }\end{array}$ \\
\hline \multicolumn{6}{|c|}{ Absolute Forecast Error ${ }_{t}=\alpha+\beta^{*}$ Uncertainty $_{t}$} \\
\hline Uncertainty $(\boldsymbol{\beta})$ & $\begin{array}{l}-0.65 \\
(0.64)\end{array}$ & $\begin{array}{c}1.27 \\
(1.08)\end{array}$ & $\begin{array}{l}1.16 \\
(0.80)\end{array}$ & $\begin{array}{l}0.31 \\
(.77)\end{array}$ & \\
\hline $\begin{array}{l}\text { Test: } \beta=0 \\
\text { (No information) }\end{array}$ & $\mathrm{p}=0.32$ & $\mathrm{p}=0.25$ & $\mathrm{p}=0.16$ & $\mathrm{p}=0.69$ & $\mathrm{p}=0.26$ \\
\hline $\begin{array}{l}\text { Test: } \beta=1 \\
\text { (Efficient forecast) }\end{array}$ & $\mathrm{p}=0.02$ & $\mathrm{p}=0.81$ & $\mathrm{p}=0.84$ & $\mathrm{p}=0.37$ & $\mathrm{p}=0.09$ \\
\hline
\end{tabular}

Notes: (Standard errors in parentheses)

${ }_{* * * * * *}^{* *}$ and ${ }^{*}$ denote statistically significant at $1 \%, 5 \%$ and $10 \%$, respectively.

Forecast errors normalized by historical standard error of survey-based forecasts.

Of course the object of interest in these regressions - the standard deviation of the state price distribution - is a summary statistic from a much richer set of digital options or density 
forecasts, and so we will obtain greater power in the next section as we turn to analyzing these density forecasts more directly.

\section{Full Distribution Implications}

A particularly interesting feature of the Economic Derivatives market is that it yields not only a point estimate, but also a full probability distribution across the range of plausible outcomes. Exploiting this, we can expand our tests beyond section 3, which asked whether the mean forecast is efficient, to also ask whether the prices of these options yield efficient forecasts of the likelihood of an economic statistic falling in a given range.

Figure 6 provides an initial analysis, pooling data from all 2,235 digital call options (contracts that pay $\$ 1$ if the announced economic statistic is above the strike price) across our 153 auctions. We grouped these options according to their prices, and for each group we show the proportion of the time that the economic statistic actually is above the strike price. These data yield a fairly close connection, and in no case do we see an economically or statistically significant divergence between prices and probabilities.

While the evidence in Figure 6 suggests that the Economic Derivatives prices are unbiased, it does not speak to the efficiency of these estimates, an issue we now turn to. Because density estimates are hard to come by, the forecast evaluation literature has focused on evaluating point forecasts rather than densities. An intermediate step between point and density estimate evaluation is interval forecast evaluation. An interval forecast is a confidence interval such as "nonfarm payrolls will be between 100,000 and 180,000 with 95 percent probability." Christoffersen (1997) shows that a correctly conditionally calibrated interval forecast will provide a hit sequence (a sequence of correct and incorrect predictions) that is independently and identically Bernoulli distributed with the desired coverage probability. A density forecast can be thought of as a collection of interval forecasts, and Diebold, Gunther, and Tay (1998) show that the i.i.d. Bernoulli property of individual interval forecasts translates into the i.i.d. uniform $(0,1)$ distribution of the probability integral transform, $z_{t}$, defined as

$$
z_{t}=\int_{-\infty}^{y_{t}} \pi(x) d x \stackrel{\text { iid }}{\sim} \operatorname{Uniform}(0,1)
$$


where $\pi(x)$ denotes the price of an option paying $\$ 1$ if the realized economic statistic takes on the value $x$, and $y_{t}$ is the actual realized value of economic statistic. Thus $z_{t}$ can be thought of as the "realized quantile," and the implication that this should be uniformly distributed essentially formalizes the argument that if the prediction density is correct, the ' $x$ ' percent probability event should be happening ' $x$ ' percent of the time. In the data we do not observe exact state-prices $\pi(x)$, but rather digital ranges, $\int_{a}^{b} \pi(x) d x$; to estimate the realized quantile we simply assume that $\pi(x)$ is uniformly distributed within each strike-price range.

\section{Figure 6: Prices and Probabilities - Digital Call Options}

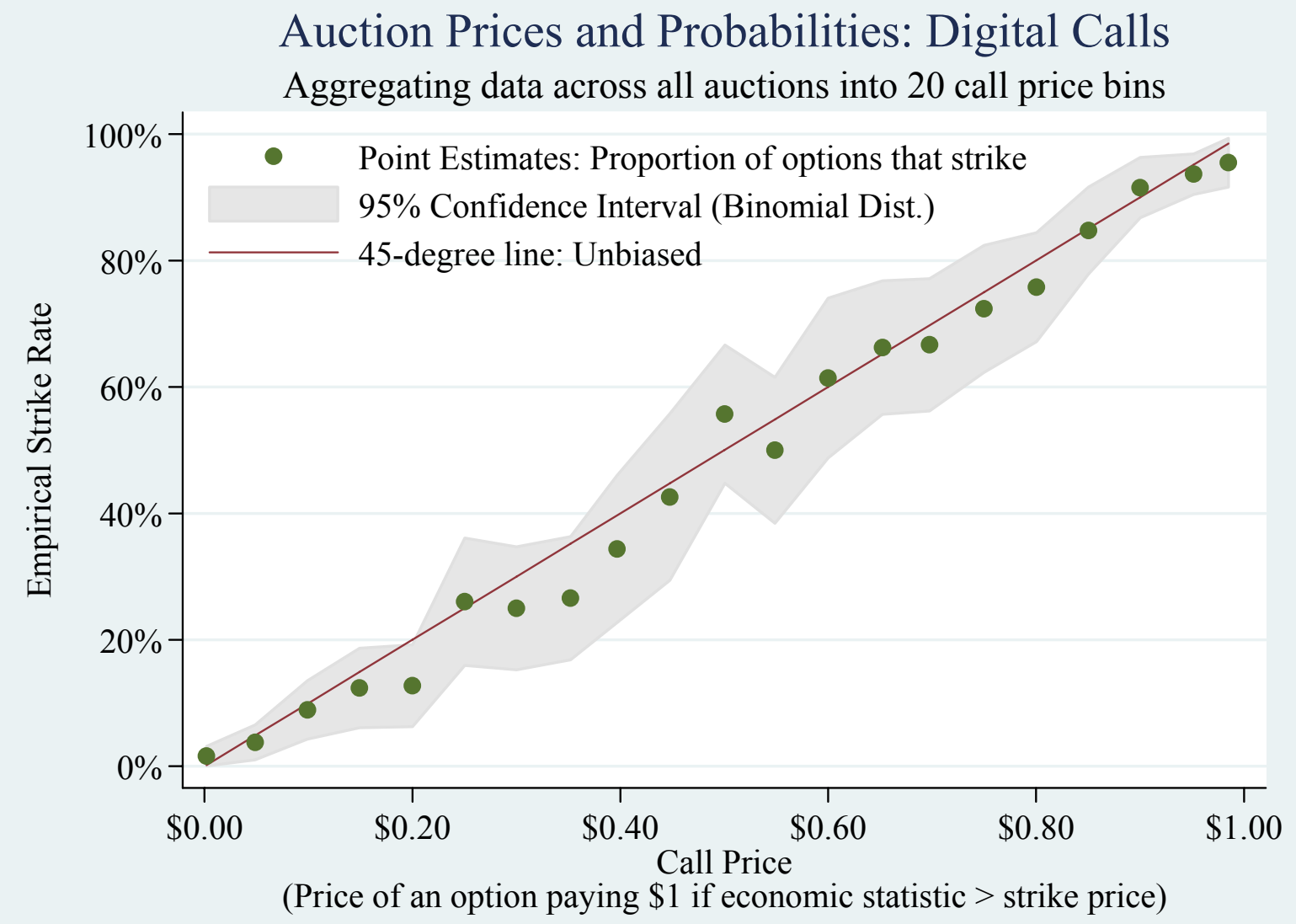

In Figure 7 we calculate the realized quantile for each auction, pool the estimates across different economic statistics and plot the relevant histogram. A simple way to test for deviations from uniformity derives from inverting the earlier logic: if the distribution is uniform, then the probability that any given realization is in any given bin should follow a 
Bernoulli distribution with the hit probability equal to the width of the bin, and hence the number of realizations in each bin should follow a binomial distribution. Thus in Figure 7 we show the relevant $95 \%$ critical values under the assumption of i.i.d. uniformity.

Figure 7. Histogram of Realized Quantiles

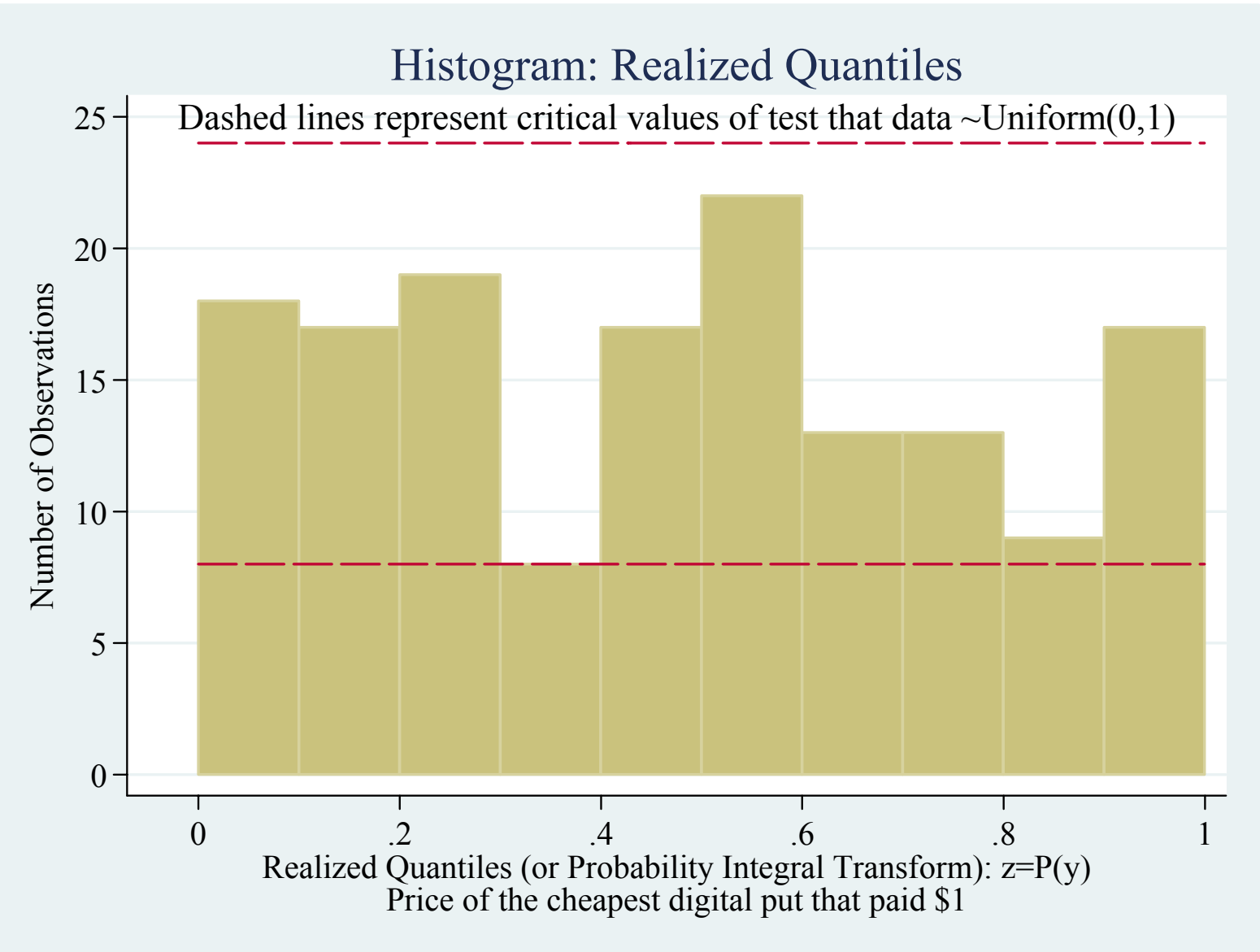

Figure 7 shows that the distribution is generally close to uniform, albeit with a peak around 0.5 , which is suggestive of excess realizations close to the median forecast. That said, this distribution is statistically indistinguishable from a uniform distribution. ${ }^{15}$

The inference in this figure is partly shaped by the specific bin widths chosen for the histogram. Figure 8 shows an alternative representation, mapping both the entire cumulative distribution function of the probability integral transform and the uniform distribution. The

\footnotetext{
${ }^{15}$ Note that the critical values are appropriate for each bin separately, but they are inappropriate for jointly testing that the heights of all bins are drawn from a binomial distribution.
} 
figure also shows the deviations from uniformity that would be required for a KolmogorovSmirnov test to reject a null that the realized quantiles are drawn from a uniform distribution. As seen, this suggests that the data are fairly close to an idealized uniform $(0,1)$ distribution, and that these data yield no statistically significant evidence falsifying this null.

Figure 8. Cumulative Distribution Function of Realized Quantiles

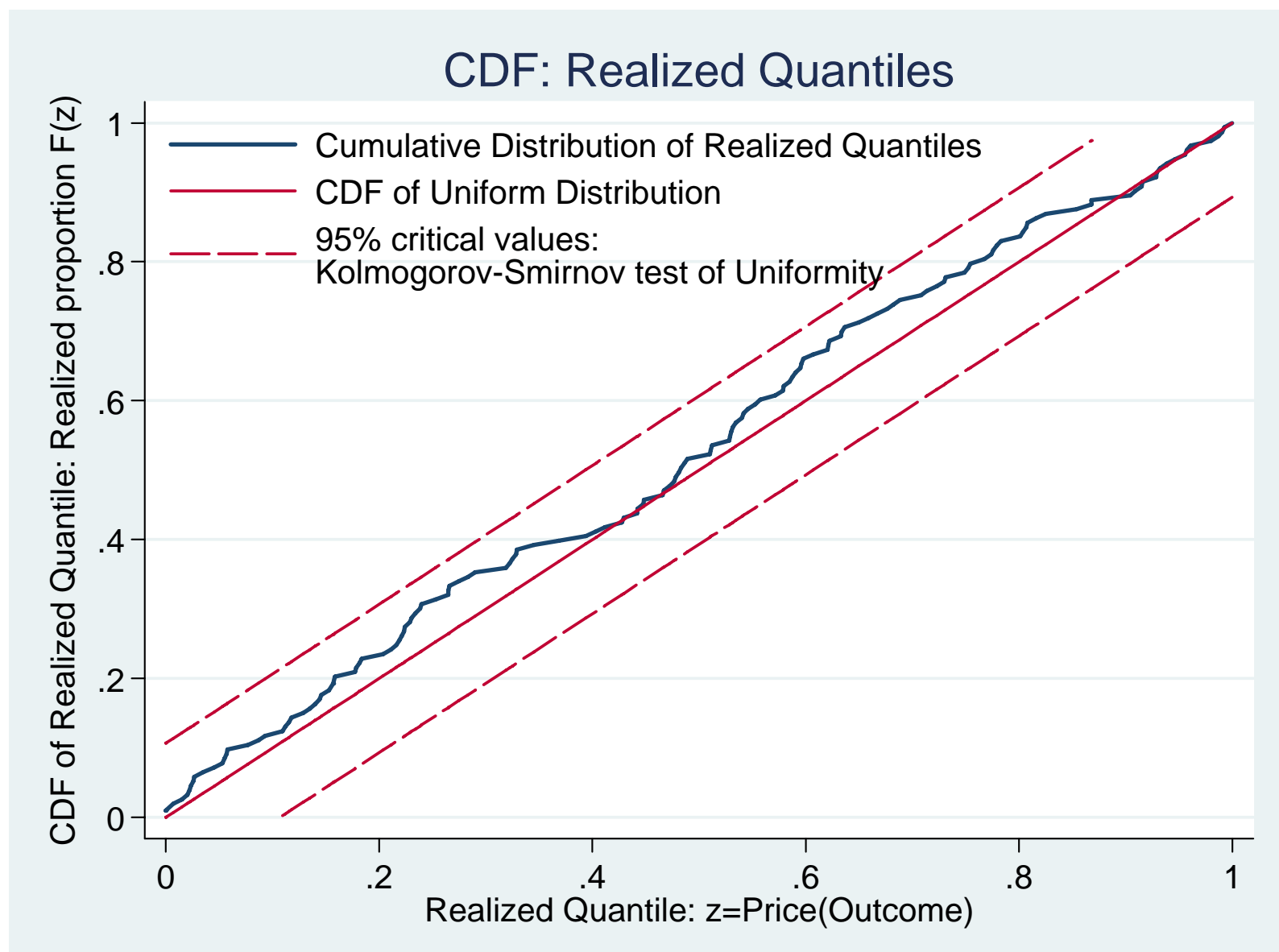

Delving deeper, Figure 9 plots the same transformed variable for each data series separately. 
Figure 9. Cumulative Distribution Function of Realized Quantiles, by Data Release

CDF: Realized Quantiles

Dashed lines show 95\% Kolmogorov-Smirnov critical values under null z $\mathrm{U}(0,1)$

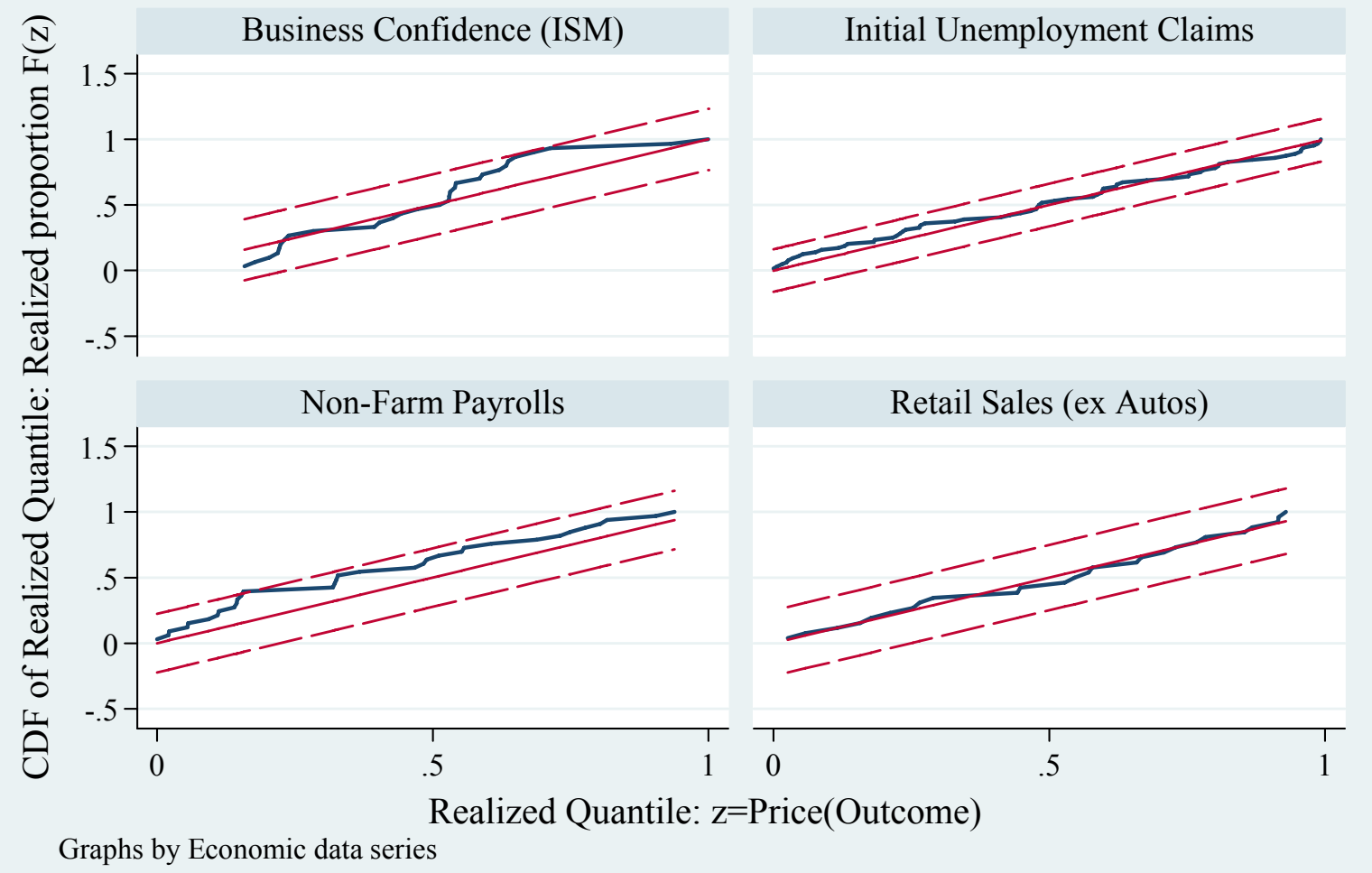

Disaggregating the realized quantile by data series confirms that there is little evidence of non-uniformity of these distributions although there are some interesting hints of small miscalibrations in density forecasts. In particular, the ISM CDF is too steep in the central section, suggesting that too few realizations fall in the tails of the forecast distribution. The non-farm payrolls probability integral transform series is also very close to the upper critical value, suggesting too many realizations in the left tail. Neither of these leads to a rejection of the uniform distribution null hypothesis, however.

Figures 8 and 9 show that the economic derivatives based density forecasts have correct coverage. Efficient density forecasts also require independence of the probability integral transform variables over time. We therefore now turn to examining the time series of the probability integral transforms in Figure 10. 
Figure 10. Time Series of Probability Integral Transforms

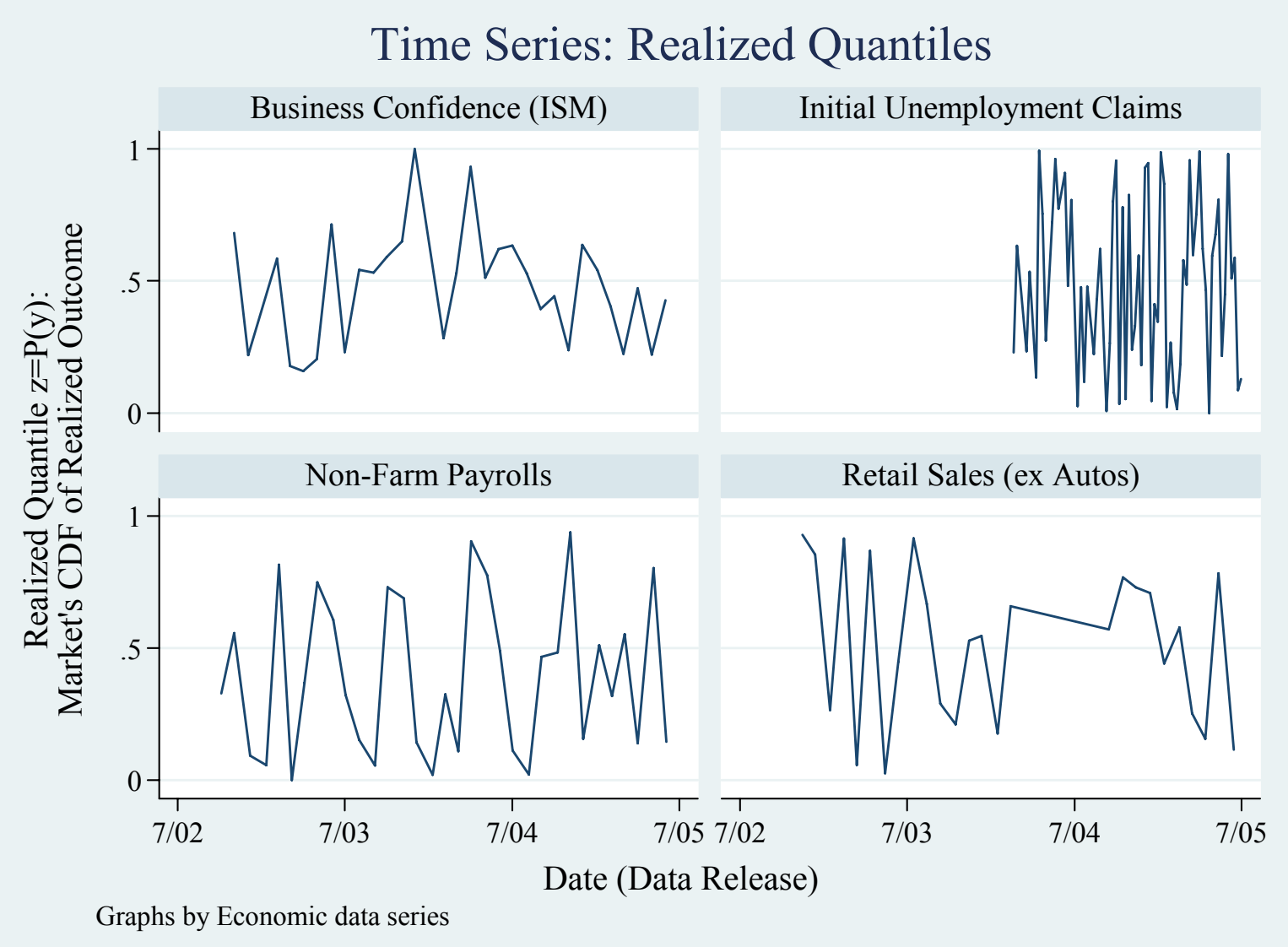

The time series plots do not suggest any clear time series correlation. To be sure, we have run simple AR(3) models, and found no statistically significant evidence of autocorrelation.

Finally we turn to a test that allows us to test jointly for both serial independence and uniformity of the realized quantile, maximizing our statistical power. Berkowitz (2001) notes that there exist more powerful tests for deviations from normality than from uniformity, particularly in small samples. He suggests analyzing a normally-distributed transformation of the probability integral transform. Specifically, he advocates analyzing:

$$
n_{t}=\Phi^{-1}\left(z_{t}\right)=\Phi^{-1}\left(\int_{-\infty}^{y_{t}} \pi(x) d x\right)
$$


where $\Phi^{-1}\left(z_{t}\right)$ is the inverse of the standard normal distribution function. Thus, if $z_{t}$ is iid $\sim \mathrm{U}(0,1)$, then this implies that $n_{t}$ is iid $\sim \mathrm{N}(0,1)$. We can thus test this null against a first-order autoregressive alternative allowing the mean and variance to differ from $(0,1)$ by estimating:

$$
n_{t}-\mu=\rho\left(n_{t-1}-\mu\right)+\varepsilon_{t}
$$

We estimate this regression by maximum likelihood. Berkowitz shows the exact loglikelihood function for the univariate case; it is simple to adapt this to the case of an unbalanced panel as in the present case:

$L=\sum_{t=1}^{\text {Unobs. Lag }}\left[-\frac{1}{2} \log (2 \pi)-\frac{1}{2} \log \left(\frac{\sigma^{2}}{1-\rho^{2}}\right)-\frac{\left(n_{s, t}-\mu /(1-\rho)\right)^{2}}{2 \sigma^{2} /\left(1-\rho^{2}\right)}\right]+\sum_{i=1}^{\text {observe Lag }}\left[-\frac{1}{2} \log (2 \pi)-\frac{1}{2} \log \left(\sigma^{2}\right)-\frac{\left(n_{s, t}-\mu-\rho n_{s, t-1}\right)^{2}}{2 \sigma^{2}}\right]$

where the first term aggregates over observations where the lagged dependent variable is not observed, and the second term aggregates over all others.

Table 8 reports our estimation results. Estimating 3 parameters across each of 4 data series we find only two coefficients that are individually statistically distinguishable from the efficiency null. For each series we perform a likelihood ratio test that jointly tests whether the estimated models significantly deviate from the efficiency null. For none of our series is there significant evidence that the realized quantiles violate the iid uniform requirement. Finally, in order to maximize our statistical power we pool the estimates across all four indicators, and once again the test suggests that these density forecasts are efficient.

The evidence presented in this section shows that economic derivatives option prices are accurate and efficient predictors of the densities of underlying events. This finding is surprising in the sense that asset prices usually embed a risk premium due to risk aversion and for this reason tend to be systematically biased - a bias that does not seem to be present in this market. The implications of risk and risk aversion in the pricing of economic derivatives are the subjects of the next section. 
Table 8: Testing for Autocorrelation in the Probability Integral Transform

\begin{tabular}{lccccc}
\hline & $\begin{array}{c}\text { Non- } \\
\text { farm } \\
\text { Payrolls }\end{array}$ & $\begin{array}{c}\text { Business } \\
\text { Confidence }\end{array}$ & $\begin{array}{c}\text { Retail Sales } \\
\text { (ex autos) }\end{array}$ & $\begin{array}{c}\text { Initial Claims } \\
\text { Pooled } \\
\text { data }\end{array}$ \\
\hline \multicolumn{2}{c}{$n_{t}-\mu=\rho\left(n_{t-1}-\mu\right)+\varepsilon_{t}$ where } & $n_{t}=\Phi^{-1}\left(\int_{-\infty}^{\text {Outcome }_{t}} \pi(x) d x\right)$ & \\
Mean $(\boldsymbol{\mu})$ & $-0.46^{* *}$ & 0.03 & 0.04 & -0.04 & -0.10 \\
& $(.19)$ & $(.15)$ & $(.17)$ & $(.15)$ & $(.09)$ \\
Variance $\left(\boldsymbol{\sigma}^{2}\right)$ & 1.05 & 0.70 & 0.76 & $1.46^{*}$ & 1.16 \\
& $(.26)$ & $(.18)$ & $(.21)$ & $(.26)$ & $(.13)$ \\
Autocorrelation $(\boldsymbol{\rho})$ & -0.11 & 0.23 & -0.31 & 0.05 & 0.001 \\
& $(.17)$ & $(.26)$ & $(.19)$ & $(.13)$ & $(.09)$ \\
LL $\left(\hat{\mu}, \hat{\sigma}^{2}, \hat{\rho}\right)$ & -18.20 & -12.59 & -11.45 & -51.45 & -100.42 \\
LL $(0,1,0)$ & -21.34 & -13.65 & -12.82 & -54.19 & -101.99 \\
LR Test & 6.27 & 2.12 & 2.73 & 5.48 & 3.16 \\
& $(\mathrm{p}=0.10)$ & $(\mathrm{p}=0.55)$ & $(\mathrm{p}=0.44)$ & $(\mathrm{p}=0.14)$ & $(\mathrm{p}=0.37)$ \\
Sample size & 33 & 30 & 26 & 64 & 153 \\
\hline
\end{tabular}

Notes: (Standard errors in parentheses)

${ }^{* * *},{ }^{* *}$ and ${ }^{*}$ denote statistically significant deviations from the null at $1 \%, 5 \%$ and $10 \%$, respectively. Forecast errors normalized by historical standard error of survey-based forecasts.

\section{The Role of Risk}

Thus far we have interpreted the prices of digital options as density forecasts - an approach that would be warranted if investors were risk-neutral. Yet options and option markets exist precisely because there is risk, and it seems plausible that agents willingly pay a risk premium for the hedge offered by macroeconomic derivatives. We now turn to assessing the magnitude of this risk premium. To preview, we find that for an investor who holds the S\&P 500 portfolio the aggregate risks that are hedged in these markets are sufficiently small that for standard assumptions about risk aversion the premium should be close to zero. Further, we show that option prices are typically quite close to the empirical distribution of outcomes. We then explore the corollary of these results, investigating what the pricing of these options implies about risk aversion.

Using option prices to make inference about risk and risk aversion is not a new idea, but is seldom attempted in the literature due to the complications arising from properties of standard options - complications that are not present in the economic derivatives market. In important papers, Jackwerth (2000) and Aït-Sahalia and Lo (2000) analyzed options on the S\&P 500 to derive measures of risk aversion. Using economic derivatives to measure 
perceived risk and risk attitudes is far easier for several reasons. First of all, the options in these markets provide direct readings of state-prices; these do not have to be constructed from portfolios of vanilla options. More importantly, since the options expire within the same day of the auction, time discounting is not an issue and the discount factor can be set to zero. Similarly none of the concerns arising from the presence of dividends are present here.

To illustrate the relationship between risk aversion and the pricing of economic derivatives, we start by considering a representative investor who is subject to some risk that with probability $p$ will change her wealth to $\beta$ percent of its current value, $w$. The investor can buy or sell economic derivatives to protect herself against this shock. We consider the purchase of a derivative that pays $\$ 1$ per option purchased if the event occurs. Thus, the investor chooses how many derivatives to purchase $(x)$ at a price $\pi$ to maximize her expected utility:

$$
\underset{\{x\}}{\operatorname{Max}} E U(w)=p U(\beta w+(1-\pi) x)+(1-p) U(w-\pi x) .
$$

The first-order condition yields an optimal quantity of options, $\mathrm{x}^{*}$ :

$$
\frac{U^{\prime}\left(\beta w+(1-\pi) x^{*}\right)}{U^{\prime}\left(w-\pi x^{*}\right)}=\frac{\pi(1-p)}{p(1-\pi)}
$$

That is, the investor purchases options until the marginal rate of substituting an additional dollar between each state is equated with the ratio of the marginal cost of transferring a dollar between states.

Because these economic derivatives are in zero net supply, in a representative agent model equilibrium requires that $x^{*}=0$, yielding the equilibrium price:

$$
\pi=\frac{p}{p+(1-p) \frac{U^{\prime}(w)}{U^{\prime}(\beta w)}}
$$

This expression yields some very simple intuitions. If $\beta$ is unity then the probability and the state price are the same regardless of the degree of risk aversion. Indeed, such an option would be redundant because there is no risk to be hedged. Alternatively if agents are risk-neutral $\left(U^{\prime}(w)=U^{\prime}(\beta w)\right)$, then again the option price represents the probability that the event will 
occur. If investors are risk averse and the option pays off following a negative shock to wealth $(\beta<1)$ then the state price is higher than the true probability.. If the option pays off following a positive wealth shock $(\beta>1)$ then the risk-averse investors will price it at a value lower than its probability. Alternatively phrased, risk aversion leads the state-price distribution to shift to the left of the probability distribution, and this shift is larger the smaller the ratio $U^{\prime}(w) / U^{\prime}(\beta w)$; that is, distribution shifts further left for more risk-averse investors, and for larger adverse shocks.

Extending this logic to the case where the investor is subject to many possible shocks, and where there are markets available for her to hedge each risk is somewhat cumbersome, but yields only a minor modification. Specifically, the investor may face a variety of shocks where each specific shock, indexed by $i$, changes wealth to $\beta_{i}$ percent of baseline and occurs with probability $p_{i}$. Investors hedge these risks so as to maximize expected utility by purchasing $x_{i}$ options at price $\pi_{i}$, and each such option pays $\$ 1$ if the specified shock occurs. We refer to $\pi_{i}$ as a state-price, and the distribution as the state-price distribution. The representative consumer's problem is:

$$
\operatorname{Max}_{\left\{x_{i}\right\}} E[U(w)]=\sum_{i} p_{i} U\left(\beta_{i} w+x_{i}-\sum_{j} \pi_{j} x_{j}\right)
$$

We combine the first-order condition with the pari-mutuel mechanism constraint that total premiums paid should cover total payoffs in all states of the world $\left(\forall i: x_{i}=\sum_{j} \pi_{j} x_{j}\right)$, to derive the following fairly intuitive expression for the risk premium:

$$
\frac{\pi_{i}}{p_{i}}=\frac{U^{\prime}\left(\beta_{i} w\right)}{\sum_{j} p_{j} U^{\prime}\left(\beta_{j} w\right)}
$$

In Figure 11 we use this equilibrium relationship to assess the relationship between state prices and probabilities at different levels of risk aversion. Specifically, to make this exercise relevant to assessing the pricing of economic derivatives, we solve for the entire state-price distribution when the investor risks being hit by wealth shocks that are drawn from a normal distribution. In this example a one-standard deviation negative shock causes wealth to decline by $1 \%$ (That is, $\beta=1+0.01 z$ where $z \sim \mathrm{N}(0,1)$ ). We calculate option prices for the log- 
utility case $(\gamma=1)$, a substantially more risk averse case $(\gamma=5)$ at the upper end of values usually assumed to be plausible by macroeconomists, and for a level of risk aversion typically thought implausible, but required to generate the observed equity premium $(\gamma=20)$.

Figure 11. Risk Aversion and State-Price Distributions

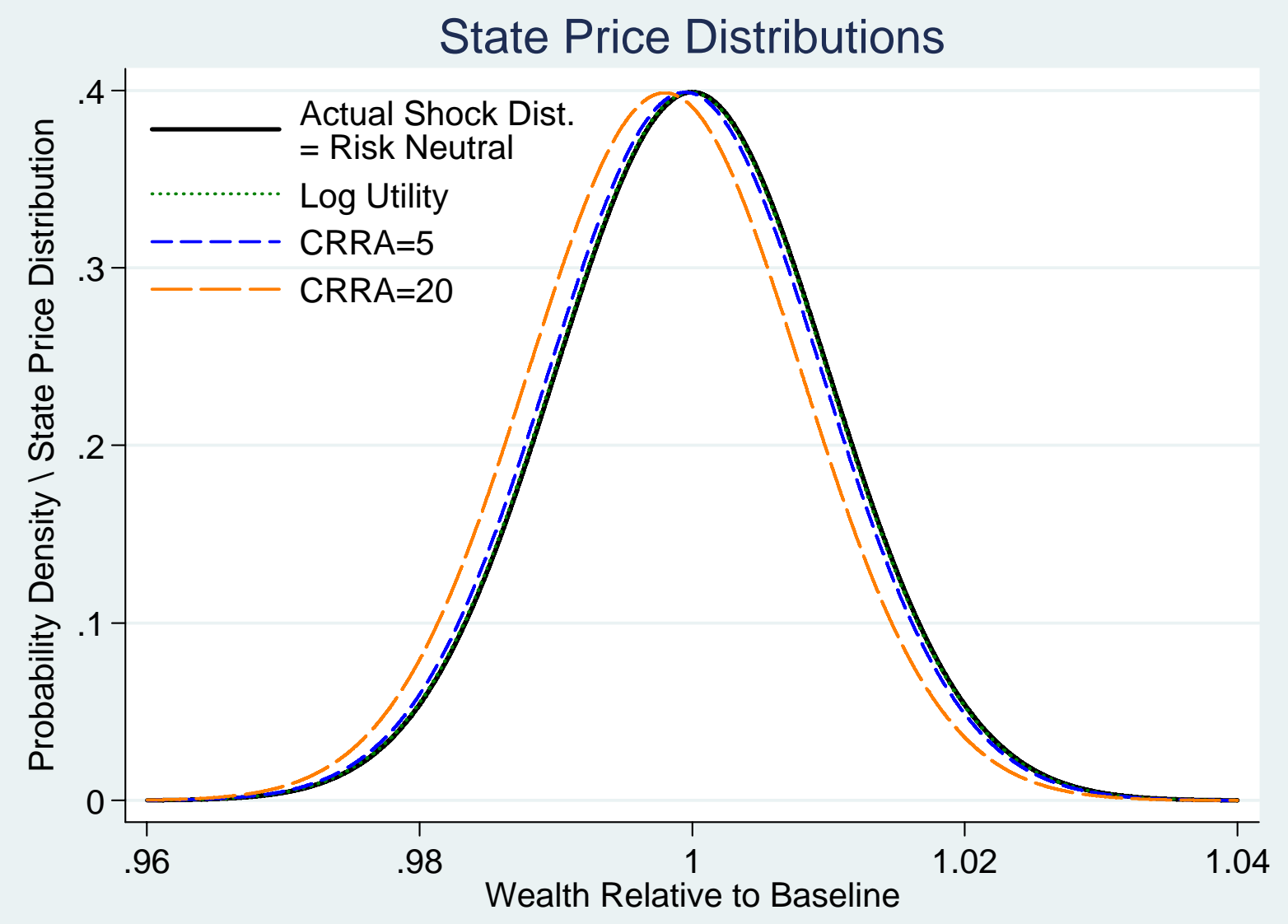

As can be seen fairly clearly, for standard levels of risk aversion, the price distribution closely resembles the risk-neutral distribution. Increasing risk-aversion shifts the distribution to the left and the higher the risk aversion the more the state-price and data generating distributions are different.

More generally, our option pricing formula allows us to utilize data on any two objects out of the utility function, the distribution of shocks and the state prices, to make inferences about the risk premium. In order to assess the likely magnitude of the risk premium, we begin by analyzing the divergence between the state-price distribution and the shock distribution that 
would be implied by specific utility functions and the economic shocks we see in our data. This requires us first to map the relationship between economic shocks and changes in wealth, then to map the empirical distribution of such economic shocks, before plugging these data into the above equation to back out the risk premium suggested by the theory.

Our analysis in section 3 (and specifically Figure 2) shows that the economic statistics have important effects on equity and bond markets. Backing out the implications of these shocks for wealth requires us to be more precise about a specific model of the economy. We assume complete markets, which implies the existence of a representative investor (Constantinides, 1982). Following Jackwerth (2000) and Ait-Sahalia and Lo (2000) we assume that movements in the S\&P 500 are representative of shocks to the entire stock of wealth. While one might be concerned that news about the economy affects different sectors differently, these are diversifiable risks, and so with complete markets should not affect wealth. Thus to recover the shock to wealth that macroeconomic derivatives allow one to hedge, we analyze the stock-market response to economic shocks in Table 9. That is, we run:

$$
\Delta S \& P 500_{t}=\alpha+\beta *\left(\text { Actual }_{t}-\text { Forecast }_{t}^{\text {Economic Derivs }}\right)
$$

As before, we examine changes in the 30 minute window around the announcement, and we scale the forecast error by the historical standard deviation of forecast errors for that series.

Table 9: Effects of Economic News on the S\&P 500

\begin{tabular}{|c|c|c|c|c|}
\hline $\begin{array}{l}\text { Dependent variable: } \\
\% \triangle S \& P 500\end{array}$ & $\begin{array}{l}\text { Non-farm } \\
\text { Payrolls }\end{array}$ & $\overline{I S M}$ & $\begin{array}{c}\text { Retail Sales (ex } \\
\text { autos) }\end{array}$ & $\begin{array}{l}\text { Initial } \\
\text { Claims }\end{array}$ \\
\hline $\begin{array}{l}\text { Actual }_{\boldsymbol{t}}-\text { Forecast }^{\text {Economic Derivs }}{ }_{\boldsymbol{t}}{ }^{\text {(Normalized by historical SD) }}\end{array}$ & $\begin{array}{l}+0.37 \% \\
\quad(.10)\end{array}$ & $\begin{array}{l}+0.11 \% \\
\quad(.11)\end{array}$ & $\begin{array}{l}+0.04 \% \\
\quad(.06)\end{array}$ & $\begin{array}{c}-0.01 \% \\
(.02)\end{array}$ \\
\hline $\begin{array}{l}\text { Adjusted } R^{2} \\
n\end{array}$ & $\begin{array}{c}0.31 \\
33\end{array}$ & $\begin{array}{c}0.005 \\
30\end{array}$ & $\begin{array}{c}-0.03 \\
26\end{array}$ & $\begin{array}{c}-0.006 \\
64\end{array}$ \\
\hline
\end{tabular}

Notes: Forecast errors normalized by historical standard error of survey-based forecasts. (Standard errors in parentheses)

${ }^{* * *},{ }^{* *}$ and ${ }^{*}$ denote statistically significant at $1 \%, 5 \%$ and $10 \%$, respectively.

As expected, we find that positive shocks to non-farm payrolls, business confidence and retail trade are positive shocks to wealth, while higher initial claims is a negative shock. Comparing columns, it is clear that the non-farm payrolls surprise is easily the most important 
shock. The coefficient is also directly interpretable: a one standard deviation shock to nonfarm payrolls raises wealth by $0.37 \%$ and the $95 \%$ confidence interval extends from $+0.17 \%$ to $+0.54 \%$. These magnitudes are all much smaller than those used to construct Figure 11, suggesting that the relationship between prices and probabilities is even closer than that figure suggested. More to the point, these coefficient estimates correspond to $\beta-1$ in the simple model presented above, allowing us to calculate the risk premium directly.

Rather than make specific parametric assumptions, we simply observe the distribution of different sized economic shocks in our data, and use a kernel density smoother to recover the shock distribution, using the estimates in Table 9 to rescale forecast errors into the corresponding wealth shocks. In this framework the frequency of specific shocks, their effects on wealth, and assumptions about risk aversion are sufficient to yield an estimate of the expected risk premium embedded in any particular strike price. Consequently in Figure 12 we show the state price distribution that the theory implies, based on the empirical shock distribution and assumptions about risk aversion. The risk-premium is simply the difference between the state price distribution, and the risk-neutral or empirical shock distribution.

Clearly for most plausible utility functions the risk premium is extremely small. Indeed, for log utility the risk premium is less than one percent of the price even for very extreme outcomes. Even with rates of constant relative risk aversion as high as five, the risk premium is still essentially ignorable; the only real exception to this is the non-farm payrolls release, which constitutes a much larger shock to wealth. In that instance, the price of an option with a strike price two standard deviations from the mean may be inflated by around 4 percent (and hence a call option would be priced at $\$ 0.026$ instead of $\$ 0.025$ ). If the relevant relative risk aversion parameter is as high as 20 , then the data suggest that option prices might be somewhat more biased. 


\section{Figure 12: Effects of Risk on the State Price Distribution}

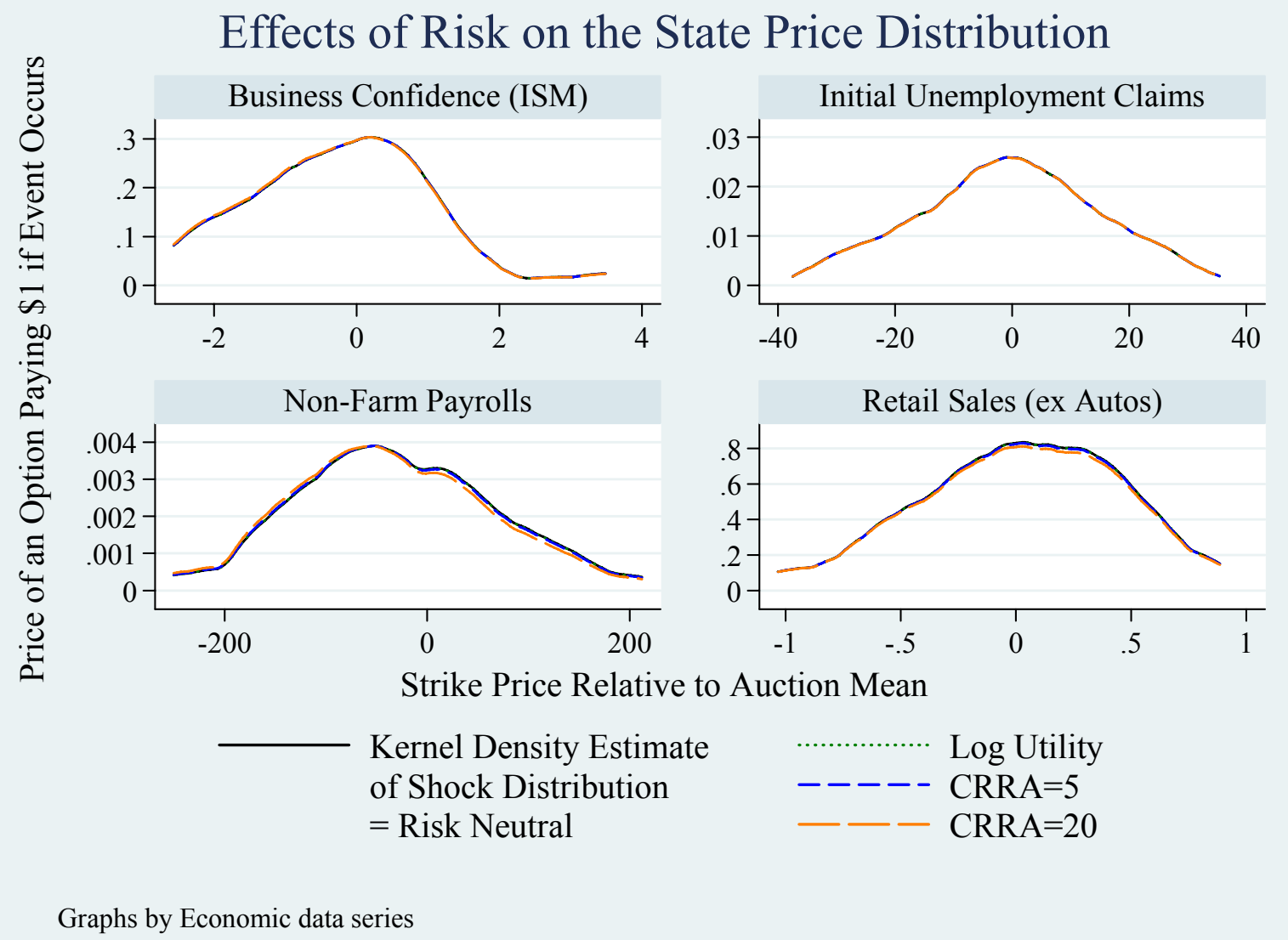

Of course, for many applications, the mean forecast implicit in the state price distribution is the object of interest. Thus in Table 10 we compute the difference between the mean of the state price distribution and the mean of the underlying probability distribution for different values of assumed risk aversion. Again these numbers are based on the empirical distribution of shocks, although assuming normally distributed shocks yields similar magnitudes. Our aim is simply to provide a rule-of-thumb adjustment for calculating the mean of the probability distribution from the widely reported mean of the auction price distribution.

Panel A shows that, under risk aversion, the mean of the state price distribution will under-estimate the mean of the risk-neutral ("true") distribution for the three pro-cyclical series, but will lead to a minor overstatement of initial claims, which is countercyclical. The adjustments in Panel A are in the same underlying units as the statistics are reported in, and hence suggests, for instance, that if the relative risk aversion of investors is five, then the mean 
of the state price distribution understates the mean forecast by about 1600 jobs. Panel B presents these same results in a metric that better shows that these magnitudes are small, scaling the risk-premium adjustment by the standard error of the forecast. In each case the bias from simply assuming risk-neutrality is less than one-tenth of a standard error, and in most cases, it is orders of magnitude smaller.

Table 10: Measures of Central Tendency of the Probability and State-Price Distribution

\begin{tabular}{|c|c|c|c|c|}
\hline & $\begin{array}{l}\text { Non-farm } \\
\text { Payrolls }\end{array}$ & ISM & $\begin{array}{c}\text { Retail Sales } \\
\text { (ex autos) }\end{array}$ & Initial Claims \\
\hline \multicolumn{5}{|c|}{ Panel A: Risk Premium: } \\
\hline Risk-Neutral $(\gamma=0)$ & 0 & 0 & 0 & 0 \\
\hline Log Utility $(\gamma=1)$ & -0.32 & -0.001 & -0.0002 & 0.002 \\
\hline Risk-Averse $(\gamma=5)$ & -1.60 & -0.005 & -0.0009 & 0.008 \\
\hline Extremely Risk Averse $(\gamma=20)$ & -6.40 & -0.021 & -0.0034 & 0.033 \\
\hline \multicolumn{5}{|c|}{ Panel B: Risk Premium } \\
\hline Risk-Neutral $(\gamma=0)$ & 0 & 0 & 0 & 0 \\
\hline Log Utility $(\gamma=1)$ & -0.0028 & -0.0005 & -0.0005 & 0.0001 \\
\hline Risk-Averse $(\gamma=5)$ & -0.0137 & -0.0028 & -0.0023 & 0.0004 \\
\hline Extremely Risk Averse $(\gamma=20)$ & -0.0553 & -0.0107 & -0.0094 & 0.0018 \\
\hline
\end{tabular}

Notes: In panel A, the units are thousands of non-farm payroll jobs, points on the ISM index, percentage growth in retail sales, and thousands of initial claims. Panel B measurements are relative to a one standard deviation shock.

While Table 10 suggests that risk should lead the market-based forecast to be only slightly lower than the risk-neutral forecast, we can take advantage of the time series movement in uncertainty to test this. ${ }^{16}$ In Figure 13 we show forecast errors and uncertainty for each data series. In no case is the regression line statistically significant, suggesting that the data do not falsify the implications in Table 10 that the slope should be approximately zero. Notice that this exercise is slightly different from the one in Table 10 as here we look at the consequences of time-variance in the amount of risk, while in Table 10 the amount of risk is implicitly taken as invariant but the price of risk changes.

\footnotetext{
${ }^{16}$ We thank Jeffrey Frankel for suggesting this test to us.
} 


\section{Figure 13: Uncertainty and Risk Premia}

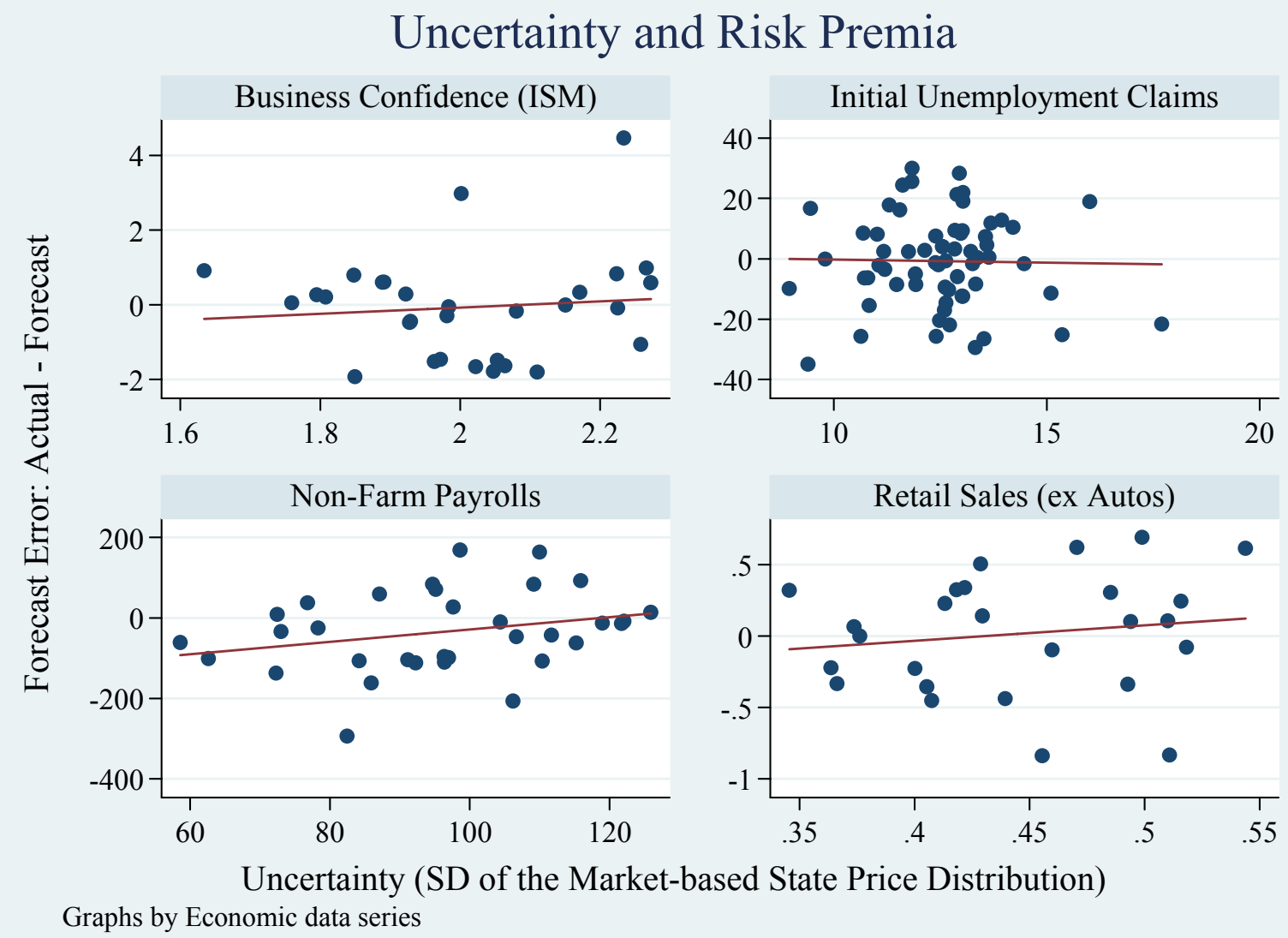

In sum, Figure 12 and Table 10 imply that under standard assumptions about risk, the state price distribution is a reasonable approximation to the true underlying probability distribution, and this conclusion holds even when we make fairly extreme assumptions about risk aversion. Indeed, Figure 13 and our analysis of the probability integral transform in the previous section confirmed precisely this point and in most cases market prices provided quite successful estimates of empirical realizations.

Figure 14 makes this point in an alternative manner, pooling the data across all auctions within each data series to map both the empirical shock distribution and the average state price distribution. The two appear remarkably close given the limited number of observations identifying the distribution of outcomes. 


\section{Figure 14: State Price Distribution and the Distribution of Outcomes}

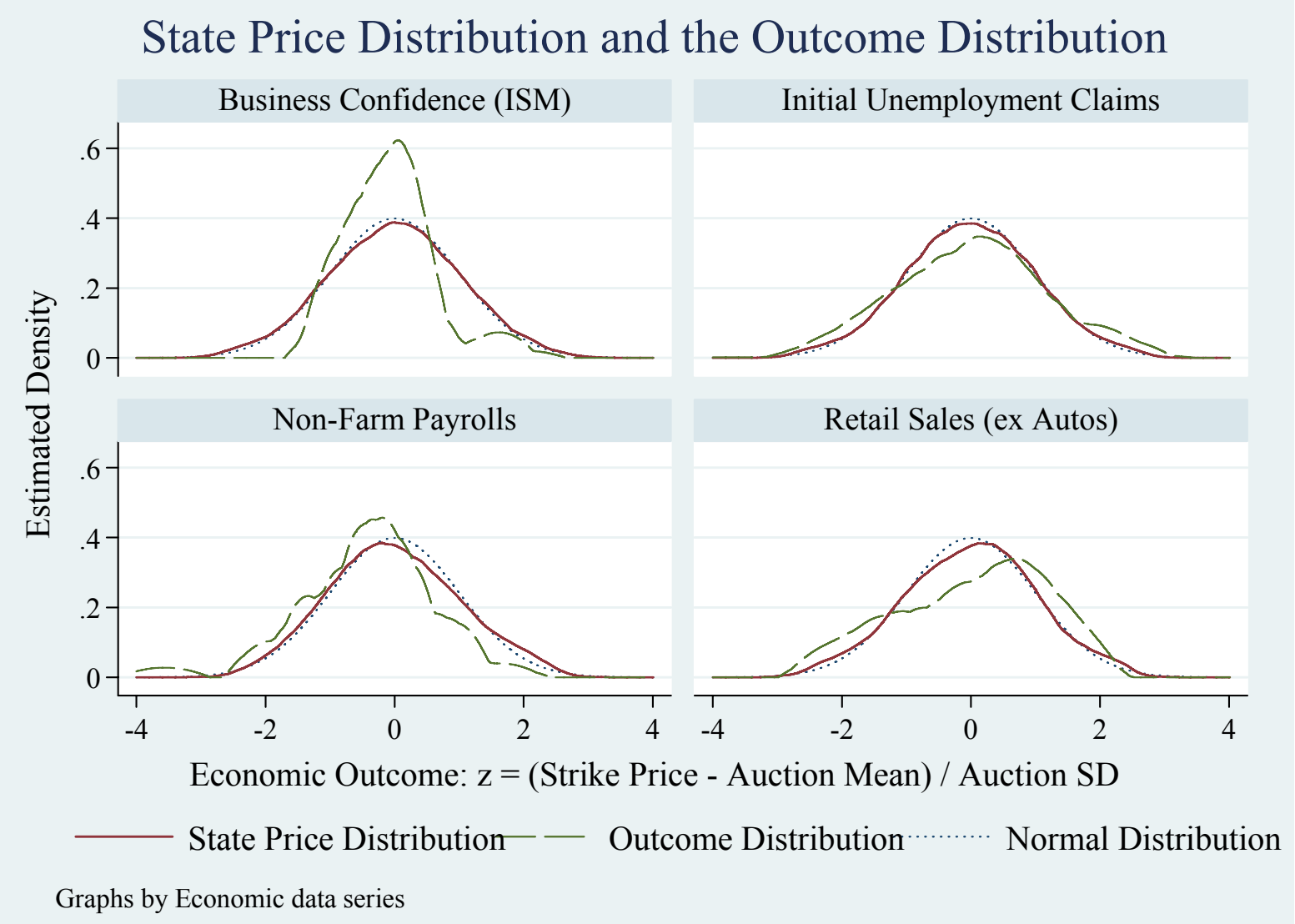

Our option-pricing formula also suggests that we can compare option prices and observed outcomes to back out an estimate of risk aversion. Indeed, under the assumption of constant relative risk aversion of $\gamma$, our option pricing formula directly yields a log-likelihood function:

$$
L=\sum_{a}^{\text {Auctions }}\left[\log \left(\pi_{a}^{*}\right)+\gamma \log \left(\beta_{a}^{*}\right)-\log \left(\sum_{s}^{\text {Strikes }} \pi_{s, a} \beta_{s, a}{ }^{-\gamma}\right)\right]
$$

where auctions are indexed by $a$ and digital options within each auction are further indexed by $s$, the asterisk indexes the winning digital option, and thus $\pi^{*}$ and $\pi_{s, a}$ come from the data, while estimates of the wealth impacts of shocks, $\beta_{i}$ are taken from Table 8 , and $\beta^{*}$ is the relative wealth position given the observed shock.

We pooled all of our data to estimate the coefficient of relative risk aversion $(\gamma)$, but these data do not yield much power: the $95 \%$ confidence interval around our estimate of $\gamma$ 
extends from -182 to +27 , with a central estimate that suggests risk-loving behavior. This is readily apparent in Figure 13, which shows that the state price distribution is to the right of the outcome distribution for non-farm payrolls, and to the left of the outcome distribution for the counter-cyclical initial claims data. (As Figure 12 shows, risk aversion would suggest the opposite pattern.)

However, rather than highlight our point estimate, we regard its enormous imprecision as arguably more interesting. ${ }^{17}$ This imprecision derives from the fact that under our complete market assumptions the economic risks that can be hedged in this market are sufficiently small that alternative views about risk aversion do not affect all that much how one would price options tied to these risks. From an estimation standpoint this implies small amounts of noise in the option prices potentially yield very different implications for point estimates of implied risk aversion. Again, Figure 12 is instructive: essentially our estimates suggest that the data cannot distinguish between any of the state price distributions drawn on that figure, and given how close they are, this is not particularly surprising.

Thus while this market does not yield particularly useful estimates of risk aversion, the flipside is that this is driven by the fact that option prices are relatively insensitive to assumptions about risk aversion. From a practical perspective this is good news: the option prices that we observe in this market are a reasonable approximation to the risk-neutral distribution.

\section{Conclusions}

In this paper we provided a first analysis of the option prices from the new economic derivatives market. Economic derivatives (which have an interesting, pari-mutuel, market clearing mechanism) are novel because these binary options are written on economic data releases and state-prices of different strikes provide information not only about markets' central belief but also about implied probabilities of outcomes away from the mean. This information is not available from surveys.

We dwelled on several aspects of the economic derivatives, starting with their predictive performance. These options appear to yield efficient density forecasts, a rarity.

\footnotetext{
${ }^{17}$ Note that when estimating implied risk aversion in this fashion, we treated the $\beta_{\mathrm{i}}$ as known. The confidence interval would have been even wider had we accounted for the variance imparted by having the $\beta$ 's estimated.
} 
Knowing that event probabilities are correctly priced in this market makes inference using the dispersion statistics convincing. In particular, this justifies using the option-based standard deviation to measure uncertainty about a data release. Comparing uncertainty with disagreement, the standard deviation of survey responses, showed that these two measures of dispersion do not have a high degree of correlation. It may not be advisable to use disagreement as a proxy for uncertainty.

The density forecast efficiency tests, when applied to market-based measures, are joint tests of efficient pricing and absence of risk premia. Our finding that economic derivatives based densities are efficient therefore indicate that risk premia in this market is unlikely to be sizable. We exploited the institutional structure of economic derivatives to study risk and risk aversion. This is quite straightforward when options from this market are used, compared to using S\&P 500 options, which require taking into account time discounting and dividends. We believe economic derivatives are promising instruments for economists who would like to use asset prices to learn about agents' beliefs and preferences.

We should emphasize that we view this paper as an initial exploration. We showed that economic derivatives correctly capture subjective beliefs and provided some applications of this information. Having these subjective probabilities will facilitate future research to study how expectations are formed and how they relate to actions, as well as to analyze agents' responses to occurrence of events of different prior subjective probabilities. 


\section{References}

1. Aït-Sahalia, Yacine and Andrew W. Lo (2000), "Nonparametric Risk Management and Implied Risk Aversion," Journal of Econometrics, 94, 9-51.

2. Baron, Ken and Jeffrey Lange (2003), "From Horses to Hedging," Risk, 16(2), 73-7.

3. Berkowitz, Jeremy (2001), "Testing Density Forecasts, With Applications to Risk Management," Journal of Business and Economic Statistics, 19(4), 465-474.

4. Constantinides, George (1982), "Intertemporal Asset Pricing with Heterogeneous Consumers and without Demand Aggregation," Journal of Business, 55(2), 253-76.

5. Diebold, Frank X., and Todd Gunther, and Anthony S. Tay (1998) "Evaluating Density Forecasts, With Applications to Financial Risk Management," International Economic Review, 39, 863-883.

6. Diebold, Frank X., Jinyong Hahn, and Anthony S. Tay (1999), "Multivariate Density Forecast Evaluation and Calibration in Financial Risk Management: High-Frequency Returns on Foreign Exchange," Review of Economics and Statistics, 81, 661-73.

7. Diebold, Frank X., Anthony S. Tay and Kenneth F. Wallis (1999), "Evaluating Density Forecasts of Inflation: The Survey of Professional Forecasters," in R. Engle and H. White (eds.), Festschrift in Honor of C.W.J. Cranger, (Oxford: Oxford University Press), 76-90.

8. Eisenberg, Edmund and David Gale (1959), "Consensus of Subjective Probabilities: The Pari-Mutuel Method," Annals of Mathematical Statistics, 30, 165-68.

9. Fair, Ray C. and Robert J. Shiller (1990), "Comparing Information in Forecasts from Econometric Models," American Economic Review, 80(3), 375-89.

10. Gürkaynak, Refet S., Brian Sack, and Eric Swanson (2005), "Did Financial Markets Think Disinflation Was Opportunistic?” manuscript, Federal Reserve Board.

11. Jackwerth, Jens Carten (2000), "Recovering Risk Aversion from Option Prices and Realized Returns," The Review of Financial Studies, 13(2), 433-51.

12. Jackwerth, Jens Carten and Mark Rubinstein (1996), "Recovering Probability Distributions from Option Prices," Journal of Finance, 51(5), 1611-31.

13. Llambros, Louis and Victor Zarnowitz (1987), "Consensus and Uncertainty in Economic Prediction,” Journal of Political Economy, vol. 95 (3), pp. 591-62.

14. Mankiw, N. Gregory, Ricardo Reis, and Justin Wolfers (2003), "Disagreement about Inflation Expectations," NBER Macroeconomics Annual, 18, 209-48. 
15. Shiller, Robert (1993), Macro Markets, Oxford: Oxford University Press.

16. Wolfers, Justin and Eric Zitzewitz (2004), "Prediction Markets," Journal of Economic Perspectives, 18(2), 107-26.

17. Wolfers, Justin and Eric Zitzewitz (2005), "Interpreting Prediction Market Prices as Probabilities", mimeo, University of Pennsylvania. 